\title{
Mesoscale Partitioned Modelling of Masonry Bridges Allowing for Arch- Backfill Interaction
}

\author{
Yanyang Zhang ${ }^{a, b}$, Enrico Tubaldi ${ }^{a}$, Lorenzo Macorini ${ }^{a}$, Bassam A Izzuddin ${ }^{a}$ \\ ${ }^{a}$ Department of Civil and Environmental Engineering, Imperial College London, South \\ Kensington Campus, London, UK, SW7 2AZ \\ ${ }^{b}$ Key Laboratory of Transportation Tunnel Engineering, Ministry of Education, Southwest \\ Jiaotong University, Chengdu, Sichuan, China, 610031
}

Keywords: Masonry arch bridge; arch-soil interaction; backfill; nonlinear analysis; masonry mesoscale description.

\begin{abstract}
Masonry arch bridges exhibit a complex three-dimensional behaviour which is determined by the interaction between different structural and non-structu33ral components, including the arch barrel, the backfill and the lateral walls. This paper presents an advanced finite-element modelling strategy for studying the behaviour of masonry arch bridges under vertical loading which combines a mesoscale description of the arch barrel with a plasticity-based continuum approach for the fill and the spandrel-walls. The proposed modelling strategy is validated against available experimental laboratory test results on masonry arch bridges. Firstly, a bridge specimen with a detached spandrel wall is analysed considering a simplified strip model. Subsequently, the influence on the bridge response of backfill and arch characteristics, loading position, arch shape and abutment movements are investigated through a comprehensive parametric study. In the final part of the paper, the results of full 3D mesoscale simulations of an arch bridge with attached spandrel walls are presented and discussed. The analysis results provide significant information on the complex interaction between the different bridge components along the longitudinal and transverse direction, and can be used to validate and calibrate simplified approaches for practical assessment of masonry arch bridge.
\end{abstract}




\section{Introduction}

The realistic behaviour of masonry bridges is determined by the interaction between arch barrel, backfill, spandrel- and wing-walls, and masonry piers in the case of multi-span bridges. In practical assessment, fill material is considered as a non-structural component and its contribution is often neglected or it is allowed for by using simplified approaches. However, as confirmed by previous experimental and numerical research [1], the backfill plays a critical role spreading the loads applied on the road/rail surface to the arch barrel, and it provides transverse resistance and passive pressure to the deformed arch. Thus, a realistic representation of the fill behaviour and its interaction with the masonry arch is critical for an accurate response prediction of masonry arch bridges. For this reason, the backfill contribution has been accounted for since the development of the early 1D nonlinear descriptions for masonry bridges, as the finite element (FE) modelling strategies set out by Crisfield [2] and Choo et al. [3] using nonlinear beam elements for representing the masonry arch and nonlinear axial springs to simulate the backfill. In subsequent research, masonry arch and backfill have been represented using different 2D approaches, including discontinuous deformation analysis, discrete element techniques and nonlinear FE descriptions [4], where 1D nonlinear interface elements have been adopted to represent the interaction between the arch and the backfill as well as the development of cracks in the mortar joints of the arch. More recently, Cavicchi \& Gambarotta [5, 6] investigated the effect of the archbackfill interaction on the structural behaviour of multi-span masonry arch bridges using nonlinear beams with an elastic-plastic no-tension material model for arches and piers, where the backfill has been simulated using a 2D plain strain FE representation with a modified Mohr-Coulomb plastic criterion allowing for material nonlinearity. These previous numerical descriptions are generally efficient as they are based on 1D or 2D reduced models, but in many cases they lead to a crude representation of the actual bridge behaviour, which is inherently three-dimensional [7]. More recently, 3D numerical models for masonry bridges have been proposed, and a continuous nonlinear FE strategy with solid elements has been employed, where the masonry components are represented using a macroscale material model which assumes masonry as a homogeneous and isotropic material [8-10], thus neglecting the orthotropic texture of masonry. An alternative advanced 3D modelling strategy has been put forward by Milani \& Lourenço [11], where the masonry components are modelled using a homogenised approach with rigid solid elements and nonlinear interfaces, allowing to account for masonry orthotropy. 
In this paper, a detailed 3D description is proposed for masonry bridges utilising a mesoscale strategy for brick/block-masonry [12]. In previous research [13, 14], it was shown that this advanced modelling strategy enables an accurate response prediction of masonry arches, as it takes into account the actual masonry bond, including potential defects in the brickwork, without resorting to homogenization techniques as in [11]. This numerical approach is extended here to allow for the interaction between arch and backfill. Because of the significant computational cost, the proposed detailed description with solid elements for masonry units and backfill and 2D nonlinear interface elements for mortar joints is coupled with a partitioning approach previously developed at Imperial College [15, 16] allowing for parallel processing on High Performance Computing systems. The mesoscale masonry model, the elasto-plastic description for the backfill and the partitioning strategy have been implemented in ADAPTIC [17], a general finite element code for nonlinear analysis of structures under extreme loading conditions, which is used in this study to perform accurate numerical simulations of masonry arch bridges. Using the proposed modelling strategy, two multi-ring arch bridges, previously tested at the Bolton Institute [18], are modelled in this paper. The two bridges are identical except for the spandrel walls, which in one case are detached providing only a transverse restraint to the backfill, while in the other case they are attached furnishing also a significant contribution to the global stiffness and resistance. Numerical predictions are first compared against test results for the case with detached spandrel walls, and the results of an extensive parametric study are then presented. This has been conducted on a simplified strip bridge model to investigate the influence of the backfill and the arch characteristics, the loading position, the arch shape and the abutment movements on the bridge response. In the final part of the paper, the results of a full 3D mesoscale analysis of the bridge model including the contribution of the spandrel walls are presented and discussed to show the unique capabilities of the proposed modelling approach for unveiling the complex interaction of the masonry components along the longitudinal and transverse direction.

\section{Modelling strategy for masonry bridges}

Accurate modelling of brick/block-masonry should take into account not only the mechanical characteristics of units and mortar but also the actual 3D masonry texture. This is disregarded in most of the numerical strategies currently used for nonlinear analysis of masonry arches, in which the arch domain is represented using 2D models based on the plane strain assumption. 
While this could be generally acceptable for the analysis of square arches subjected to line loads, it may lead to erroneous results when investigating the response of arches under patch loads or skew arches exhibiting an inherent 3D response [7]. The adopted numerical strategy for brick/block-masonry, which follows the mesoscale description previously developed at Imperial College [12], allows for an accurate representation of the actual masonry bond and the 3D geometry of any masonry arch including skew arches [13].

\subsection{D mesoscale description for masonry arch}

A discrete modelling strategy is used for the masonry arch, where zero-thickness nonlinear interface elements are adopted to represent mortar joints and solid elements to model masonry units. In this way, typical fracture lines, which characterise the nonlinear response up to collapse of masonry arches in masonry bridges under gravity and traffic loading, can be represented. These correspond to radial cracks, circumferential cracks leading to ring separation in multi-ring arches, and longitudinal cracks caused by transverse bending [7]. While the first two types of crack generally take place in mortar joints, longitudinal cracks may also pass through masonry units. Thus, nonlinear interface elements are also placed in the middle of each bricks to capture potential development of cracks. These are utilised along with 20-noded elastic solid elements, formulated according to standard FE procedures [19], for representing the brick units. In the following, only the main characteristics of the adopted nonlinear interface elements are provided, while more detailed information can be found in [12].

The nonlinear interface elements used to represent mortar joints and capture potential cracks in masonry units have 16 nodes, each of which features three translational freedoms. In the constitutive model for the adopted interface element, material nonlinearity is taken into account employing a cohesive model, which enables an effective representation of damage, cracks and plastic separations. In particular, a multi-surface plasticity criterion is utilised with two separate yield functions (Figure 1a). Firstly, a hyperbolic plastic surface $F_{1}$ based on the Coulomb slip criterion determines the boundaries of elastic domain in tension and shear representing Mode-I and Mode-II fracture, as defined by:

$$
F_{1}=\tau_{x}^{2}+\tau_{y}^{2}-(C-\sigma \tan \phi)^{2}+\left(C-\sigma_{t} \tan \phi\right)^{2}
$$

where $C, \sigma_{t}$ and $\tan \phi$ are cohesion, tensile strength and tangent of the friction angle for a mortar joint or a brick-brick interface. A non-associated flow rule is employed and a plastic potential $Q_{1}$ similar to function $F_{1}$, but with a different friction angle parameter, is adopted to 
model the actual dilatancy. This is due to the roughness of the fractured shear surface and can be measured in tests on interfaces. The second yield function $F_{2}$ corresponds to a cap model in compression and it is described by another hyperbolic function:

$$
F_{2}=\tau_{x}^{2}+\tau_{y}^{2}-(D-\sigma \tan \theta)^{2}+\left(D-\sigma_{c} \tan \theta\right)^{2}
$$

where $\sigma_{c}$ is the compressive strength of masonry while $D$ and $\theta$ are material parameters governing the shape of the cap surface.

For a realistic representation of the development of cracks in the brickwork, a work-softening plasticity approach is employed and two distinct historical parameters expressed in the form of plastic work values, namely $W_{p l l}, W_{p l 2}$, are associated with the two yield functions governing the degradation of the material parameters. This enables the representation of decohesion and loss of friction at the interface. In particular, the tensile strength and the friction angle converge to their residual values (material parameters) when $W_{p l l}$ approaches the Mode-I fracture energy $G_{f l}$; similarly the cohesion at the interface reaches its residual value when $W_{p l l}$ converges to the Mode-II fracture energy $G_{f I I}$. Figure1b shows the tractionseparation response in tension, where it can be observed that the use of very large $G_{f I}$ values moves towards a perfectly plastic behaviour with no strength degradation in tension.

\subsection{Modelling of backfill}

As in previous research [7-10], the backfill is represented using a continuum strategy with an elasto-plastic material description. In particular, 15-noded elasto-plastic tetrahedral elements are employed to model the fill domain and a specific plastic criterion is use to describe the development of plastic deformations. Backfill in existing masonry bridges is largely made from soil materials, thus realistic soil models should be considered for an accurate description of the backfill contribution in masonry arch bridges. Numerous constitutive models have been proposed for representing the nonlinear behaviour of soil [20], which are generally formulated within the elasto-plastic framework utilising different plastic criteria. Usually the most advanced models, capable of reproducing the complex soil response with high accuracy, require a large number of input parameters which cannot be easily obtained from conventional tests. Consequently, in structural simulations aimed at investigating soilstructure interaction as in the analysis of masonry bridges, simpler isotropic elastic-perfectlyplastic models, such as the Mohr-Coulomb and the Drucker-Prager models, are usually adopted. The first model results from the combination of Hooke's law and Coulomb's failure criterion and requires two elastic parameters, Young's modulus and Poisson's ratio, and only 
two inelastic parameters, namely cohesion and friction angle, for defining the plastic surface. The Mohr-Coulomb model allows for an accurate description of the soil behaviour at failure, but adopting constant Young's modulus and Poisson's ratio values, it provides only an approximate linear response prediction before reaching the plastic limit. The Drucker-Prager model [21] is a simplification of the Mohr-Coulomb model, as it substitutes the irregular hexagonal cone representing the boundaries of the elastic domain with a cylindrical cone in the principal stress space providing significant computational advantages. However, as traditional soil mechanics predictions are based upon Mohr-Coulomb parameters, which can be obtained in standard tests, it is preferable to adopt the Mohr-Coulomb plastic formulation also in numerical simulations [20]. Nevertheless, some computational difficulties must be solved, mainly to deal with the corners of the yield and plastic potential surfaces. In particular, at the edges of the hexagonal cone, the gradients of the yield function and the plastic potential as well as the gradient derivatives are not uniquely defined, thus preventing the solution of the local plastic problem using standard techniques [22]. In this study, a modified Drucker-Prager (DP) yield criterion is developed with enhanced numerical robustness. In this respect, the yield surface (Figure 2a) encompasses two smoothly intersecting yield functions, the first one being the Drucker-Prager envelope function, while the second one is a circular tensile cap which limits the tensile resistance of the material while circumventing numerical problems due to the singularity at the apex of the original Drucker-Prager yield function. The first yield surface $F_{1, D P}$ and associated plastic potential $Q_{1, D P}$ are defined by:

$$
\begin{aligned}
& F_{1, D P}(\xi, \rho)=\sqrt{6} \alpha \xi+\rho-\sqrt{2} k=0 \\
& Q_{1, D P}(\xi, \rho)=\sqrt{6} \alpha_{d} \xi+\rho-\sqrt{2} k_{d}=0
\end{aligned}
$$

where $\xi=\frac{1}{\sqrt{3}} I_{1}$ and $\rho=\sqrt{2 J_{2}}$ depend respectively on the first invariant $I_{l}$ of the stress tensor and the second deviatoric stress invariant $J_{2}$, while $\alpha, k$ and $\alpha_{\mathrm{d}}, k_{d}$ are material parameters determining the shape of the yield and plastic potential surfaces.

The expression for the second yield surface and plastic potential is given by:

$$
F_{2, D P}=G_{2, D P}=\sqrt{\rho^{2}+\left(\xi-\xi_{c}\right)^{2}}-r=0
$$

where $\xi_{c}$ and $r$ denote the centre and the radius of the circular cap, which are expressed as: 


$$
\begin{aligned}
& \xi_{c}=\chi-\frac{\xi_{\max }-\chi}{\sqrt{1+\left(\frac{\xi_{\max }}{\rho_{0}}\right)^{2}}-1} \\
& r=\frac{\xi_{\max }-\chi}{\sqrt{1+\left(\frac{\xi_{\max }}{\rho_{0}}\right)^{2}}-1}
\end{aligned}
$$

where

In (6) and (7) $\chi \leq \xi_{\max }$, where $\xi_{\max }$ indicates the maximum value allowed for $\xi$ under isotropic tensile stresses. Since the Drucker-Prager yield surface is a smooth version of the MohrCoulomb yield surface, it can be expressed in terms of the cohesion $c_{f}$ and the angle of internal friction $\varphi_{f}$ which are the material parameters for the Mohr-Coulomb yield surface. Thus, the Drucker-Prager material parameters can be calculated based on $c_{f}$ and $\varphi_{f}$ values considering the intersection of the Drucker-Prager yield surface either at the outer edges or at the inner edges of the Mohr-Coulomb yield surface (Figure 2b) [23]. Intersection at the inner edges is usually recommended, which can be obtained by assuming:

$$
\begin{gathered}
\alpha=\frac{2 \sin \left(\varphi_{f}\right)}{\sqrt{3}\left(3+\sin \left(\varphi_{f}\right)\right)} \\
k=\frac{6 c \cos \left(\varphi_{f}\right)}{\sqrt{3}\left(3+\sin \left(\varphi_{f}\right)\right)}
\end{gathered}
$$

The values of $\alpha_{d}$ and $k_{d}$ can be evaluated by substituting the friction angle $\varphi_{f}$ with the dilatancy angle $\varphi_{d}$ in (8) and (9). The soil material model described above has been implemented in ADAPTIC [17] following the strategy detailed in [24]. To validate the model implementation, numerical simulations have been carried out comparing the numerical results against analytical predictions found in the literature on the response of a strip footing resting on clay [25]. The footing is subjected to a uniformly distributed patch load over a length of $1570 \mathrm{~mm}$ which is increased up to failure. A description with 144 20-noded quadratic solid elements restrained along the transverse direction to represent plain strain condition is adopted for the soil material. This is characterised by Young's modulus $E_{f}=207 \mathrm{MPa}$, 
Poisson's ratio $v_{f}=0.3$, friction and dilatancy angle $\phi_{f}=\phi_{d}=20^{\circ}$, and cohesion $c_{f}=0.069$ MPa. Numerical simulations have been performed considering an associated modified DP model fitted to the inner and outer edges of the MC yield surfaces, as well as a hyperbolic associated MC model [26]. Figure3a shows the deformed shape and the contours of vonMises equivalent plastic deformations for a vertical displacement below the footing of $40 \mathrm{~mm}$ calculated using the DP soil model fitting the inner edges of the MC yield surface. It can be seen that plastic deformations localize on slip planes similar to those assumed by Terzaghi for evaluating the load carrying capacity of the foundation-soil system [25]. Figure $3 b$ depicts the numerical curves obtained employing the different soil elasto-plastic models and representing the variation of the maximum vertical displacement under the footing $d$ against the applied load $q$. In the same figure, load bearing capacity predictions for the rigid foundation obtained using Prandtl and Terzaghi theories [25] are also shown. It can be seen that the different curves show the same elastic response but a different inelastic behaviour. The DP yield surface fitted to the outer edges of the MC yield surface leads to a significant overestimation of the footing capacity. On the other hand, the DP yield surface fitted to the inner edges of the MC yield surface provides a capacity prediction which is quite close to the analytical solutions and to the numerical curve obtained employing a MC yield surface. Considering these results, the DP yield surface fitted to the inner edges of the MC yield surface is employed for representing the plastic behaviour of the backfill in the numerical analysis of masonry arch bridges.

\subsection{Arch-backfill interaction and spandrel walls}

The elasto-plastic formulation for soil materials presented in the previous section enables a realistic description of the backfill behaviour, but cannot simulate adequately the physical interaction at the interface between the fill and the masonry arch. Physical tests on real masonry bridges $[27,28]$ and laboratory models $[18,29]$ showed that significant sliding at the arch-fill interface may develop at collapse together with extensive cracks in the masonry components of the bridge. In this respect, a rigid connection among the nodes of the arch and the fill at their interface does not enable the representation of potential separation and sliding between the two domains, and may also restrain the development of radial and longitudinal cracks in the masonry arch. Thus, in the proposed 3D modelling strategy for masonry arch bridges, the discrete model with solid elements and nonlinear interfaces for the masonry arch is connected to the discretised model of the backfill by nonlinear interface elements, enabling relative movements between the two domains. In particular, the FE mesh for the backfill is 
constructed with the rectangular face of 15-noded solid wedge elements at the bottom of the backfill, where it rests on the arch, coincident with the top face of the solid elements representing masonry bricks at the extrados of the arch. In this way, as shown in Figure 4, 16noded nonlinear interface elements can be easily arranged to connect the two separate domains, where one interface element connects the top face of one 20-noded solid element modelling a portion of the arch and the bottom rectangular face of the corresponding 15noded solid element for the fill. The same nonlinear model employed for representing cracks in the brick-masonry mesoscale description is also considered for modelling the nonlinear interaction between the backfill and the arch, but with different material properties. This corresponds to a phenomenological description, which accounts not only for the frictional characteristics of the physical interface between the two domains, but it also describes the nonlinear behaviour of a portion of the backfill close to the arch which is subjected to finite deformations when large relative movements between the arch and the backfill take place. This highly nonlinear behaviour cannot be effectively described using a standard elastoplastic material model for the backfill.

In the proposed 3D numerical description for masonry arch bridges, the contribution of the spandrel walls is also taken into account. In this case, only a simplified model is adopted, as the use of the same brick-masonry mesoscale description as employed for the masonry arch is problematic in the case of spandrel walls. This is due to the specific masonry bond of the lateral wall which does not allow a direct connection of the mesoscale mesh for the wall to that of the arch, since the faces of the adjacent bricks at the interface of the two masonry components are not coincident. Moreover, the use of the mesoscale description for the lateral walls would render the connection between the wall and the inner backfill impractical. Thus, in the proposed modelling approach, the spandrel wall contribution is modelled using a continuum approach, where the FE mesh for each spandrel wall is a simple lateral extension of the FE mesh for the backfill, though different material properties are obviously used for the walls and backfill. Evidently this can provide only an approximated description of the spandrel wall nonlinear response, but it enables an adequate representation of the contribution of the spandrel walls restraining lateral expansion of the backfill, which develops when vertical loads are applied on the road/rail supported by the bridge.

\subsection{Domain partitioned approach}

When analysing large masonry structures, the use of the detailed 3D mesoscale strategy for brick/block masonry is impractical, because it requires an excessive computational effort. To 
overcome this intrinsic limitation, an efficient computational strategy for brick/block masonry has been recently developed [30], where the mesoscale description is incorporated within a novel partitioned modelling approach $[15,16]$. This enables realistic response predictions also for masonry structures, where the accuracy is guaranteed by the use of a detailed mesoscale description at the structural scale. According to this strategy, a large masonry component is modelled by a parent structure which comprises super-element representing the partitioned subdomains. Dual super-elements are used for modelling the partitions as separate processes, where two-way communication between each pair of dual parent/child super-elements allows effective parallelisation of the nonlinear structural analysis simulation $[15,16]$. When applied to modelling masonry bridges, as illustrated in Figure 5, the arch and backfill descriptions are included in different partitions and the parent structure corresponds to the set of nodes at the partitioned boundary which are located at the interface between the two separate domains. Depending on the size of the problem, a different number of partitions can be used independently for the two domains to improve computational efficiency.

\section{Modelling of bridge with detached spandrel walls}

In this section, a brick-masonry arch bridge specimen with detached spandrel walls previously tested at the Bolton Institute [18] is analysed using the proposed modelling approach. Firstly, the characteristics of the bridge model and the experimental test set-up are described. Subsequently, the results obtained in the numerical simulations are discussed and compared against the experimental results.

\subsection{Bridge specimens and experimental test}

In 1995, an experimental programme including tests on four masonry arch barrels and seven single span masonry arch bridges was conducted at the Bolton Institute [18]. In particular, masonry bridges with $3 \mathrm{~m}$ and $5 \mathrm{~m}$ span were subjected to vertical line loads up to collapse. In this section, the response of the bridge specimen named Bridge 3-1 in [18] is investigated by using the proposed modelling strategy. The geometry of the bridge, which is characterised by detached spandrel walls providing only transverse restraint to the backfill, is sketched in Figure 6 and indicated in Table 1. The $3 \mathrm{~m}$ span two-ring arch barrel was built according to the stretcher method in a segmental circular shape on massive concrete foundations. The arch is $215 \mathrm{~mm}$ thick and is characterised by a 4:1 span-to-rise ratio with a springing angle of $37^{\circ}$. 
The spandrel and the wing walls are made of English bond brick-masonry. Full size Class A engineering bricks and a 1:2:9 (cement:lime:sand) mortar were used for the brickwork, while $50 \mathrm{~mm}$ graded crushed limestone was adopted for the backfill, filling the space above the arch and between the two lateral walls (spandrel and wing walls).

In the test, a vertical line load was applied at quarter span through a $2600 \times 215 \mathrm{~mm}^{2}$ steel loading beam placed on the surface of the backfill and against a reaction frame incorporating hollow jacks and three sets of prestressing tendons. The line load uniformly distributed on the backfill along almost the full width of the arch was increased monotonically until the failure of the bridge specimen. Figure 7 depicts the failure mode of Bridge 3-1 which was due to the formation of four large radial cracks (hinges) in the arch mortar radial joints.

\subsection{Model description}

Bridge 3-1 has been represented adopting an efficient strip model with only one set of solid elements along the width of the bridge specimen for the arch and the backfill meshes. This reduced representation provides accurate results in the case of square arch bridges subjected to line loads uniformly distributed along the bridge width [13] enabling an efficient representation of the contribution of rigid spandrel walls which are detached from the arch barrel but provide transverse confinement to the backfill. Figure 8 shows the proposed simplified FE model of the bridge, where the actual masonry bond of the arch on the face of the bridge is accurately represented. More specifically, nonlinear interface elements are used for describing the circumferential mortar joints connecting the two rings and transverse mortar bed joints, which are assumed to be continuous along the radial directions. This is a realistic approximation for masonry arches with stretcher bond and relatively short span. On the other hand, brick-brick interfaces are not employed in the reduced strip description, and only one elastic solid element is utilised for representing each brick unit. The adopted mesh for the backfill is not uniform and formed using 15-noded solid elements, where a linear refinement has been considered at the abutments, and at the quarter span close to the loading area. Moreover, to allow for an accurate modelling of the arch backfill interaction, the FE mesh for the backfill is constructed with the rectangular faces of the 15-noded prismatic solid elements at the bottom of the backfill coincident with the top face of the solid elements representing masonry bricks at the extrados of the arch. Coincident nodes belonging to the two domains are then connected by nonlinear interface elements to represent separation and frictional sliding at the arch-backfill interface. With regard the model boundary conditions, fixed supports have been assumed for the nodes on the two bases of the backfill domain 
extending beyond the two arch springings. Additionally, the nodes on the two lateral faces of the backfill are restrained longitudinally (along $x$ in Figure 8), and the nodes of the arch and the backfill on the two longitudinal faces of the bridges are restrained along $z$ (Figure 8). This is to prevent transverse deformations within the bridge to model the contribution of the rigid lateral walls.

The FE mesoscale description for the arch encompasses 96 20-noded elastic solid elements for the brick units, 94 nonlinear interface elements for the mortar bed joints, 48 nonlinear interface elements for the circumferential mortar joints connecting the two adjacent rings and 48 interface elements for representing the interaction between the arch and the fill. Moreover, the backfill domain is represented by 407 15-noded elasto-plastic tetrahedral elements. Thus, the bridge is described by a strip-model employing more than 7000 degrees of freedom. To improve computational efficiency, the domain partitioning approach is utilised with 7 partitions and allowing for parallel processing.

The material tests performed in the experimental program [18] did not provide sufficient information on the critical material parameters required by the adopted model. Thus, the values of the parameters of the mesoscale model for brick-masonry [13] and of the elastoplastic model for the backfill that were not available have been selected from a range of typical values, calibrated for a good fit against the experimental results. In particular, a Young's modulus $E_{b}=35000 \mathrm{MPa}$ and a Poisson's ratio $v_{b}=0.15$ are employed for the masonry units, and the normal and tangential stiffness values $K_{n}=400 \mathrm{~N} / \mathrm{mm}^{3}$ and $K_{v}=167$ $\mathrm{N} / \mathrm{mm}^{3}$, and the inelastic properties reported in Table 2 are considered for the brick-mortar interfaces. Additionally, the masonry compressive strength $\sigma_{c}=25.9 \mathrm{MPa}$ obtained in material tests [18] related to the masonry material used to build the bridge specimen, has been considered in all the numerical descriptions. It is worth noting that the elastic properties of the solid elements and of the interfaces are such that the equivalent homogenised value of the elasticity modulus of the brickwork obtained by employing the approach of Pande [31] is $16000 \mathrm{MPa}$, which is the average value of the tests carried out in [17]. The backfill domain, consisting of crushed limestone material, is modelled utilising a modified DP criterion fitted to the MC inner edges, with Young's modulus $E_{f}=200 \mathrm{MPa}$, Poisson's ratio $v_{f}=0.20$, cohesion $c_{f}=0.001 \mathrm{MPa}$, friction angle $\varphi_{f}=55^{\circ}$, and dilatancy angle $\varphi_{d}=25^{\circ}$. The adopted small cohesion value provides a good representation of the cohesionless nature of the backfill material used in the physical tests, while ensuring computational robustness. Finally, the physical interface between the arch and backfill is modelled by a mesh of nonlinear interface 
elements with negligible cohesion and tensile strength and a friction angle of $31^{\circ}$ (Table 2). In the numerical simulations, the contribution of arch and backfill self-weight has been considered assuming a unit weight $\rho_{f}=22.2 \mathrm{kN} / \mathrm{m}^{3}$ for the fill and $\rho_{m}=22.7 \mathrm{kN} / \mathrm{m}^{3}$ for masonry.

\subsection{Numerical results}

The deformed shape of the strip model at the last step of analysis is depicted in Figure 9. A typical four-hinge mechanism with radial cracks below the load, at the two springings and at three quarter span can be observed. It offers a realistic and favourable comparison against the actual collapse mode depicted in Figure 7. Numerical-experimental comparisons in term of the applied load against the vertical displacement measured on the arch at the quarter span are shown in Figure 10. A generally good agreement between the experimental and the numerical curve (Str. Mod.) is obtained, where the initial stiffness, load capacity and post-peak response measured in the test are accurately predicted by the proposed strip-model. Cracking in the arch barrel and damage at the interface between the arch and the backfill are shown at different loading levels in Figures 11a-e. Radial cracks first appear in the mortar bed joints at the quarter span just below the load (Figure 11a). Then cracking develops at the left springing (Figure 11b), which is almost simultaneously followed by cracking at the right springing (Figure 11c). Finally, the formation of the fourth radial cracks at about the three quarter span (Figure 11d) leads to a mechanism when the arch reaches the maximum load. For larger displacements (Figure 11e), significant plastic work can be also noticed at the top circumferential interface elements which reveals separation and plastic sliding at the interface between the arch and the backfill. Figure 12 shows the equivalent von Mises plastic deformations in the backfill, when the cracks progressively developed in the masonry arch. It can be observed that at low loading levels plastic deformations form below the loading area and then, as the load is increased, they develop at the bottom of the fill domain when it connects to the right haunch of the arch and close to the arch crown. Finally, plastic deformations form at the bottom of the backfill at the three quarter span of the arch. These are caused by the pressure exerted by the backfill to the arch (passive pressure) which opposes the arch sway.

\subsection{Modelling considerations}

To investigate the influence of the modelling strategy adopted to represent the contribution of the backfill and the arch-fill interaction, numerical simulations have been performed 
comparing the results obtained by the strip-model described in the previous section and those achieved using alternative simplified strategies. These include (i) a model which disregards the backfill and considers only the contribution of the arch (Arch1), (ii) a numerical description where the backfill contribution is represented only as an additional distributed load onto the arch (Arch2), (iii) a model where the backfill is described by a continuum elastic approach (Str_Ef), and (iv) a model similar to the original strip-model introduced before, but with rigid interface elements for describing the arch-fill interaction $\left(S t r \_R i\right)$.

Figure 13 compares the load-displacement response obtained using the strip-model and the two arch models (e.g. Arch1 and Arch2). Significant differences, mainly in terms of peak load and ductility capacity, can be observed. In particular, model Archl predicts an ultimate load of $150 \mathrm{kN}$, while model Arch2 obtains a load bearing capacity of $180 \mathrm{kN}$. Both predictions are well below the experimental ultimate load $P=536 \mathrm{kN}$, which is very close to the peak load $P=503 \mathrm{kN}$ predicted by the strip model (Str. Mod.). The difference in the response predictions of the two arch models is due to the beneficial effects due to the weight of the backfill which are accounted for only in Arch2 model. These results confirm the critical role played by the backfill which is not only associated with its self-weight, but it is also due to a more complex interaction leading to the load spreading onto the arch and the pressure exerted by the fill which opposes the arch sway. These effects, and the enhancement of the global ductility capacity, can be captured only by employing an explicit representation of the backfill as in the proposed model.

In Figure 14, the response obtained assuming the backfill as an elastic continuum domain (Str_Ef) is compared against the prediction provided by the original strip-model with an elasto-plastic backfill. Evidently, Str_Ef predicts an unrealistically high stiffness and strength. This points out that the use of a continuum description neglecting material nonlinearity for the backfill leads to an unrealistic overestimate of the backfill contribution. In this case, cracking in the arch is partially restrained by the backfill and it starts to develop at higher load levels. Similar results are obtained when neglecting the development of separation and sliding at the arch-backfill physical interface. This is shown in Figure 15, where curve Str_Ri has been determined by a strip model where the nonlinear arch is connected to the nonlinear fill domain by a mesh of rigid interfaces (e.g. elastic interfaces with $K_{n}=K_{v}=1 \times 10^{6} \mathrm{~N} / \mathrm{mm}^{3}$ ). 


\section{Parametric Study}

Further numerical analyses are undertaken here to study the influence of some material and geometric characteristics on the response prediction of single span masonry arch bridges up to collapse. The brick-masonry bridge specimen analysed in the previous section using a strip-model is considered here as the reference structure. In an initial study, masonry arches with different backfill characteristics are analysed considering also the influence of defective brickwork. Subsequently, the effects due to the loading position, and support movements are investigated. The characteristics of the masonry material used in the model validation have been used in all the simulations of the parametric investigation, apart from the models with defective circumferential joints. In all the cases, this has led to bridge collapse induced by masonry failure in shear and tension, but not in compression due to the large compressive strength of the masonry material used to build the tested masonry bridge specimen.

\subsection{Influence of backfill material properties}

Numerical simulations have been performed for Bridge 3-1 varying some critical backfill material parameters one at a time, including Young's modulus $E_{f}$, cohesion $c_{f}$ and friction angle $\varphi_{f}$. Subsequently, the response of the bridge has been obtained considering an alternative soil material for the backfill, namely clay, whose parameters have been taken from [8]. Figure 16a compares the load-displacement responses determined considering three typical Young's modulus values for the backfill: $E_{f}=50 \mathrm{MPa}, 200 \mathrm{MPa}$, and 500MPa, while Figures $16 \mathrm{bc}$ show the percentage variation, with respect to the reference case $(\mathrm{N})$, of the load bearing capacity $\Delta L L_{u}$, and of the secant stiffness at $40 \%$ of the peak load $\Delta K_{s}$. It is evident from the results that a variation of $E_{f}$ within realistic limits leads to a change in the load bearing capacity, particularly for values of $E_{f}$ lower than $200 \mathrm{MPa}$, and to a more significant variation of stiffness.

Additional numerical analyses have been conducted considering different cohesion values: $c_{f}=0.001 \mathrm{MPa}, 0.01 \mathrm{MPa}$, and $0.1 \mathrm{MPa}$ (Figure 17a) and friction angles $\varphi_{f}=50^{\circ}, 55^{\circ}$, and $60^{\circ}$ (Figure 18a). Increasing the values of these parameters yields a significant increase in the load bearing capacity and only small changes of the stiffness. In particular, the top $c_{f}$ and $\varphi_{f}$ values lead to an increase in the maximum load of $60 \%$ and $16 \%$ (Figs. 17bc \& 18bc), respectively, but only to negligible percentage variation of the stiffness. These results confirm that a good estimate of the backfill properties, and in particular of the values of the 
Young modulus and the cohesion, is paramount for an accurate simulation of the behaviour of the backfill and of its contribution to the bridge resistance.

Finally, the influence of the fill material type has been investigated by considering a cohesive material such as clay instead of the originally considered frictional limestone material. In particular, the modified DP criterion fitted to the MC inner edges already employed for limestone has been used for describing the plastic behaviour of clay, with Young's modulus $E_{f}=5.6 \mathrm{MPa}$, Poisson's ratio $v_{f}=0.20$, cohesion $c_{f}=0.1 \mathrm{MPa}$, friction angle $\varphi_{f}=\varphi_{d}=27^{\circ}$. The interface between the arch and the backfill has been described by employing the same properties as for the model with frictional limestone material for the backfill.

The numerical results (Figure 19) show that the masonry bridge with limestone backfill is characterised by a higher load capacity. The responses of the two structures are quite similar only for low values of the loading (i.e. about the same initial stiffness). For higher loading values, the bridge with limestone fill provides an enhanced resistance up to collapse. This is the result of the effect on the global resistance of the low value of the Young modulus of clay (see Figure 16), which is not sufficiently counterbalanced by the high cohesion. The distribution of plastic deformations at the peak load is slightly different for the two cases, as plastic deformations in the clay backfill are more diffused, and of higher intensity compared to the limestone backfill (Figure 20). On the other hand, the plastic work contours in the interface elements (Figure 21) reveal a similar cracking pattern and damage at the interface between the arch and the backfill domain.

\subsection{Influence of brickwork defects}

The influence of defects in the brickwork has been analysed assuming a weak circumferential mortar joint to connect the two rings of the masonry arch as in previous work [14]. The material properties for the nonlinear interface elements used to model the weak joints consider initial cohesion and tensile strength values 100 times smaller than those of the undamaged joints in Table 2 and a friction angle tangent of 0.30 .

Figure 22 compares the numerical load-displacement responses of the two models with strong and weak circumferential mortar joints. A notable reduction of the load capacity for the bridge with weak joints can observed in the figure, confirming the critical influence of defects in the brickwork on the bridge performance at collapse. Figure 23 shows the contours 
of plastic deformations in the backfill and the plastic work associated with tensile and shear failure in the interface elements of the arch at final step of the analysis. Large plastic work values can be observed in the circumferential joints connecting the two rings. They develop at a very low loading level and extend from the left haunch up to the crown of the bridge, indicating ring separation in that portion of the arch. A similar behaviour has been found in [14] when analysing the response up to collapse of brick-masonry arches.

\subsection{Influence of loading position}

In this section, the effects of the loading position on the structural behaviour of masonry arch bridges are analysed. The reference bridge (Bridge 3-1) has been investigated considering (i) a live load applied on the top surface of the backfill above the mid-span of the arch barrel (Load 1), (ii) a live load at the quarter span (Load 2) and (iii) a live load at one-eighth span (Load 3). Figure 24 depicts the three FE meshes and the loading positions investigated in this study, while Figure 25 compares the load-displacement curves obtained from the numerical analyses. In Figure 26, the plastic work contours in the interface elements of the arch barrel are presented. In all the cases, radial cracks develop below the load and at the two springings. The numerical curves confirm than the minimum load capacity is reached when the load is applied at the one-eighth span. On the other hand, the maximum load capacity is achieved when the load is applied at mid-span, which is in agreement with previous numerical results [32].

\subsection{Influence of abutment movement}

In this section, the effects of movements at the abutments are investigated. As pointed out by Mckibbins et al. [7], differential displacements at the abutments and the piers resulting from the instability of the foundations is one of the most common causes of deterioration in masonry arch bridges. Three different displacement modes have been considered, specifically vertical downward uniform displacements, horizontal inward and horizontal outward movements. In the numerical simulations, all the nodes of the left arch springing and at the base of the backfill extending from the arch to the left have been subjected to prescribed displacements, which have been increased up to collapse. Reaction forces obtained from the left abutment bottom surface and the arch left end surface are plotted against the support movement in Figure 27. In general, as observed in the case of masonry arches [14], the formation of a mechanism is associated with a significant stiffness reduction, leading to a 
softening branch in the case of the vertical settlement. However, even in this case the contribution of the backfill mitigates the force reduction. This is a consequence of the elastoplastic behaviour of the backfill, resulting in a more ductile response than that of the arch alone.

Figure 28 depicts the contours of plastic deformations in the backfill, while Figure 29 shows the plastic work in the interface elements of the arch. It can be observed that the vertical displacement at the left abutment induces the formation of two main radial cracks in the arch barrel at about the quarter and the three quarter span. In this case, the plastic deformations in the fill form at the arch-fill interface from the crack at the quarter span to the crown of the arch and extend to the top of the backfill domain. The failure mode under horizontal inward displacements is characterised by three main radial cracks at the two springings and at the crown, where a maximum compressive stress of $7.86 \mathrm{MPa}$ develops. It is well below the masonry compressive strength indicating that cracking is not associated with masonry crushing at the compressed portion of the cracked section. As in previous cases, plastic deformations in the backfill propagate above the cracks up to the top of the backfill. Finally, when the bridge is subjected to horizontal inward displacement at the left abutment, a local failure occurs at the left springing with cracks also in the masonry bed joints at the opposite haunch and plastic deformations in the backfill at the left springing and at the arch-fill interface at about the three quarter span.

To evaluate the influence of the differential vertical settlement on the bridge behaviour and collapse capacity, Bridge 3-1 model has been subjected to a vertical load at quarter span of increasing intensity until collapse, after imposing different initial abutment vertical displacements at the left abutment. Figure 30 shows the applied load against the vertical displacement measured on the arch at the quarter span for the different settlements considered, whereas Figures 31-36 illustrate the plastic work in the interface elements of the arch and the contours of plastic deformations in the backfill for different initial vertical settlements at the left abutment. It is observed that the initial vertical settlement significantly influences the global stiffness, but it does not affect the ultimate load capacity. This is a consequence of the elastic-plastic and ductile behaviour of the backfill, which provides a significant contribution to the capacity of the system, and allows the redistribution of the loads after the formation of the first cracks in the masonry following the initial settlements. 


\section{Modelling of bridge with attached spandrel walls}

In this section, the brick-masonry arch bridge previously tested at the Bolton Institute and with attached spandrel walls, denoted as Bridge 3-3 in [18], is analysed using the proposed mesoscale partitioned modelling strategy. Bridge 3-3 presents the same geometric and material properties of Bridge 3-1, which are given in Figure 6 and indicated in Table 1. The only difference is the presence of the spandrel walls of width $330 \mathrm{~mm}$, while the backfill width is equal to $2880 \mathrm{~mm}$ as in the case of Bridge 3-1.

Thanks to the symmetry of the bridge response about the vertical plane at the longitudinal axis of the bridge, a FE mesh representing only half bridge has been considered. As opposed to the strip-model, eight sets of solid elements along the width of the arch have been utilised allowing the representation of the transverse behaviour of the bridge and a more realistic description of the contribution of the lateral walls. To represent the development of continuous longitudinal cracks, nonlinear interface elements simulating the formation of cracks in masonry bricks have been introduced within the mesoscale description for the masonry elements. More specifically, large elastic stiffness values $K_{n}=10000 \mathrm{~N} / \mathrm{mm}^{3}$ and $K_{t}$ $=10000 \mathrm{~N} / \mathrm{mm}^{3}$ [12] and the inelastic properties for brick-brick interfaces in Table 2 are employed to describe potential shear and tensile cracks within masonry units. The lateral wall is modelled with 15-noded solid elements as an extension of the backfill domain. Thus in the FE mesh (Figure 37), one longitudinal strips of solid elements represents the lateral wall, and the remaining seven the backfill. The dimension of the solid elements for the lateral wall along $\mathrm{z}$ corresponds to the actual thickness of the wall equal to $330 \mathrm{~mm}$, while that for the solid elements of the backfill is $277.5 \mathrm{~mm}$. Fixed supports have been assumed at the abutments (bottom of the fill domain on the left and the right of the arch), while the transverse displacements (along $z$ in Figure 37) at the nodes on the vertical plane at the bridge longitudinal axis have been restrained to allow for the symmetry condition. The same material properties employed in the strip-model described in Section 3 have been adopted for the masonry barrel and the backfill, while for the masonry spandrel wall, an elasto-plastic behaviour with the modified Drucker-Prager yield criterion has been considered. The properties of the spandrel wall material are taken as: Young's modulus $E_{w}=4000 \mathrm{MPa}$, Poisson's ratio $v_{w}=0.20$, cohesion $c_{w}=0.20$, friction angle $\phi_{w}=30^{\circ}$, dilatancy angle $\phi_{w d}=$ $10^{\circ}$. 
The 3D model comprises 480 20-noded solid elements and 1948 16-noded nonlinear interface elements for the arch, 2035 15-noded solid elements for the backfill and the lateral walls, and 240 interface elements at the boundary between the arch and the fill. This corresponds to 77,493 degrees of freedom which makes the nonlinear analysis of the bridge impractical when using conventional computational resources with a serial code. Thus to improve computational efficiency, a partitioning scheme has been considered. This has been generated using Caim, a semi-automatic mesher developed at Imperial College [33]. A total of 36 partitions has been used, with 8 child partitions for the masonry domain and 10 child partitions for the backfill. Figure 37 shows the deformed shape at the last step of the nonlinear analysis, while Figure 38 depicts the applied load against the vertical displacement at mid-width quarter span of the arch barrel, where a good comparison is achieved against the experimental results. It is also worth noting that the bridge model with attached spandrel walls exhibits significantly higher stiffness and peak load compared to the previous model with detached spandrel walls (Figure10), where the peak load is increased by more than $30 \%$. Figure 39 shows the plastic work contours in the interface elements of the arch barrel. The mechanism is similar to that observed in the strip model, with radial cracks developing below the load, at the two springings, and at three quarter span. Figure 39 shows the displacements at the quarter span along the arch width at different loading levels. It can be seen that by increasing the load, the displacement distribution becomes less uniform, and the displacements close to the spandrel walls become notably lower than those at the mid-width of the arch. This is a consequence of the transverse effects and the interaction with the lateral walls, leading to higher values of the displacement of the arch barrel at the bridge mid-width, i.e., at the farthest location from the walls. The wall-backfill interaction and transverse effects give rise to notable plastic deformations in the backfill (Figure 41) and normal stresses in the arch (Figure 42) along the transverse direction. At higher loading level these latter may induce the development of longitudinal cracks in the arch barrel. Finally, Figures 43 and 44 show respectively the normal stresses along the longitudinal direction and the plastic deformations in the spandrel walls at the last step of the analysis. Significant plastic deformations, corresponding to formation of cracks, occur in the spandrel wall, at locations which are consistent with those observed in the experimental test. 


\section{Conclusions}

In this paper, the potential and accuracy of a newly developed detailed modelling strategy for masonry arch bridges with backfill and spandrel walls has been shown. Initially, a simplified and efficient strip-model, developed assuming detached and rigid spandrel walls, has been used in numerical-experimental comparisons on the structural response of a brick-masonry bridge. It has been shown that the proposed model enables an accurate prediction of the cracking in the arch and the actual collapse mechanism providing a good estimate of the initial stiffness and the load capacity. In this respect, the contribution of the backfill is critical, where explicit modelling of the backfill domain including its elastic and plastic characteristics is required to achieve realistic results. Moreover, it has been found that the representation of the physical interface between the arch and the backfill plays a significant role, and an adequate nonlinear description allowing for separations and plastic sliding should be used for taking into account its contribution.

The strip-model has been used in a comprehensive parametric study to analyse the influence of the backfill material and brickwork parameters on the response, along with the effects of the loading position, the geometrical characteristics of the arch and potential movement at the abutment. It has been found that varying the fill parameters within realistic limits can lead to a significant change of the initial stiffness and the ultimate load, but not in the collapse mechanism. On the other hand, defects in the brickwork may cause more substantial changes in the response, where the cracking pattern is governed by ring separation which leads to a notable reduction of the load capacity. Similar to brick-masonry arches without backfill, the loading position and the arch shape influence the development and location of the cracks in the arch, where ring separation can occur in shallow arches also with good quality brickwork. The influence of abutment settlements has also been investigated, showing the formation of different failure mechanisms for the various imposed movements. These mechanisms generally show a more ductile response when compared with the failure behaviour of masonry arches caused by support movements, which is more brittle. Moreover, vertical settlements at the base of the abutments influence significantly only the initial global stiffness of the bridge, but do not affects considerably the capacity against vertical loading. This is again the effect of the ductile behaviour of the fill material, allowing the redistribution of the loads after the formation of the first cracks in masonry following the initial settlements.

Finally, the case of the bridge with attached spandrel walls has been analysed by considering an accurate 3D model, which is required to describe accurately the transversal behaviour. The 
analysis results provide significant information on the interaction between the different bridge components, leading to a complex longitudinal and transverse response. In general, spandrel walls provide a significant contribution to the stiffness and load capacity of the bridge, and they also influence notably the transverse distribution of the loading. The discrepancy between the experimental and numerical force-displacement response curve suggests that the model employed for describing the spandrel walls should be improved, and that the use of a mesoscale approach also for these elements should be investigated. The three-dimensional modelling approach presented in this study is very useful for evaluating the safety of bridges characterized by a complex behaviour which cannot be described by employing simplified modelling approaches. It can also be used for calibrating and validating these simplifying models, and can be extended to allow the analysis of the behaviour of large multi-span masonry arch bridges under vertical loadings or other type of critical loadings such as those induced by floods.

\section{Aknowledgements}

The financial support of the European Commission through the Marie Skłodowska-Curie Individual fellowship IF ("FRAMAB", Grant Agreement 657007) for the second author is greatly acknowledged. The authors also acknowledge the High Performance Computing (HPC) Services at Imperial College for providing and supporting the required computing facilities.

\section{References}

[1] V. Sarhosis, S. De Santis, G. de Felice, A review of experimental investigations and assessment methods for masonry arch bridges. Structure and Infrastructure Engineering, 12:11 (2016) 1439-1464.

[2] M.A. Crisfield, Finite Element and Mechanism Method for the Analysis of Masonry and Brickwork Arches, Proc. $2^{\text {nd }}$. Int. Conf. on Civil and Structural Engineering Computing, Civil-Comp. Press, Edinburgh, 2, 213-10, 1985.

[3] B.S. Choo, M.G. Coutie, N.G. Gong, Analysis of masonry arch bridges by a finite element method. Proc. of 4th Rail Bridge Centenary International Conference, Edinburgh, 381-392, 1990.

[4] A. Thavalingam, N. Bicanic, J.I. Robinson, D.A. Ponniah, Computational framework for discontinuous modelling of masonry arch bridges. Computer \& Structures 79 (2001) 182130 . 
[5] A. Cavicchi, L. Gambarotta, Collapse analysis of masonry bridges taking into account arch-fill interaction, Engineering Structures 27 (2005) 605-15.

[6] A. Cavicchi, L. Gambarotta, Lower bound limit analysis of masonry bridges including arch-fill interaction, Engineering Structures 29 (2007) 3002-14.

[7] L. Mckibbins, C. Melbourne, N. Sawar, C.S. Gaillard, Masonry Arch Bridges: Condition Appraisal and Remedial Treatment, CIRIA, London, 2006.

[8] P.J. Fanning, T.E. Boothby, B.J. Roberts, Longitudinal and transverse effects in masonry arch assessment. Construction and Building Materials 15 (2001) 51-60.

[9] P.J. Fanning, T.E. Boothby, Three dimensional modelling and full scale testing of stone arch bridges. Computers \& Structures, 79 (2001) 2645-62.

[10] C. Melbourne, J . Wang, A. Tomor, G. Holm, M. Smith, P. E . Bengtsson, J. Bien, T. Kaminski, P. Rawa, P. Casas, J.R. Roca, C. Molins, Masonry Arch Bridges Background document D4.7. Sustainable Bridges. Report number: Deliverable D4.7, 2007.

[11] G. Milani, P.B. Lourenço, 3D non-linear behaviour of masonry arch bridges. Computers \& Structures 110-111 (2012) 133-150.

[12] L. Macorini, B.A. Izzuddin, A non-linear interface element for 3D mesoscale analysis of brick-masonry structures, International Journal for Numerical Methods in Engineering 85(2011) 1584-608.

[13] Y. Zhang, L. Macorini, B.A. Izzuddin, Mesoscale partitioned analysis of brick-masonry arches, Engineering Structures 124 (2016) 142-166.

[14] Y. Zhang, L. Macorini, B.A. Izzuddin, Numerical Investigation of Arches in BrickMasonry Bridges. Structure and Infrastructure Engineering, 2017, DOI:10.1080/15732479.2017.1324883.

[15] G.A. Jokhio, B.A. Izzuddin, Parallelisation of nonlinear structural analysis using dual partition super elements, Advances in Engineering Software 60 (2013) 81-88.

[16] G.A. Jokhio, B.A. Izzuddin, A dual super-element domain decomposition approach for parallel nonlinear finite element analysis. International Journal for Computational Methods in Engineering Science and Mechanics 16(2015) 188-212.

[17] B.A. Izzuddin, Nonlinear dynamic analysis of framed structures, PhD. Imperial College London (University of London), 1991.

[18] C. Melbourne, M. Gilbert, The behaviour of multiring brickwork arch bridges, Structural Engineer 73 (1995), 39-47.

[19] K.J. Bathe, Finite element procedure, Upper Saddle River, New Jersey, Prentice Hall, 1996. 
[20] D.M. Potts, L. Zdravkovic. Finite Element Analysis in Geotechnical Engineering: Theory. Thomas Telford Ltd, London, 1999.

[21] D.C. Drucker, W. Prager, Soil mechanics and plastic analysis for limit design. Quarterly of Applied Mathematics 10 (1952), 157-165.

[22] J.C. Simo, T.J.R. Hughes, Computational inelasticity, New York, 1998.

[23] E.A. de Souza Neto, D. Peric, D.R.J. Owen, Computational Methods for Plasticity: Theory and Applications, Swansea, Wiley, 2008.

[24] T. Adibaskoro, Simulations of Masonry Arch Bridges, MSc Thesis, Imperial College London, 2015.

[25] O. Zienkiewicz, C. Humpheson, R. Lewis, Associated and non-associated viscoplasticity and plasticity in soil mechanics, Geotechnique, 25 (1975) 671-689.

[26] A.J. Abbo, S.W Sloan, A smooth hyperbolic approximation to the Mohr-Coulomb yield criterion, Computers \& Structures 54 (1995) 427-441.

[27] J. Page, Load tests to collapse on two arch bridges at Preston, Shropshire and Prestwood, Staffordshire, Crowthorne, Transport Research Laboratory. Report number: Research Report $110,1987$.

[28] J. Page, Load tests to collapse on two arch bridges at Strathmashie and Barlae.

Crowthorne, Transport Research Laboratory. Report number: Research Report 201, 1989.

[29] P. Walker, C. Melbourne, Load tests to collapse of model brickwork masonry arches. Proceedings of the 8th International Brick and Block Masonry Conference, Dublin, Eire, 1988.

[30] L. Macorini, B.A. Izzuddin, Nonlinear analysis of masonry structures using mesoscale partitioned modelling, Advances in Engineering Software, 60 (2013), 58-69.

[31] G.N. Pande, J.X. Liang, J. Middleton, Equivalent elastic moduli for brick masonry, Computers and Geotechnics, 8 (1989) 243-265.

[32] G. De Felice, 2009, Assessment of the load-carrying capacity of multi-span masonry arch bridges using fibre beam elements, Engineering Structures, 31(8) (2009) 1634-1647.

[33] A. Rodriguez-Villares, E. Minga, L. Macorini, B.A. Izzuddin, An automation strategy for mesoscale partitioned analysis of complex masonry structures, Proceedings of the Fifteenth International Conference on Civil, Structural and Environmental Engineering Computing", Civil-Comp Press, Stirlingshire, UK, 2015.

\section{LIST OF SYMBOLS}

Latin upper case letters

C

Cohesion of interfaces 
D

Eb

Ef

$E_{w}$

$F_{1}$

$F_{2}$

$F_{1, D P}$

$F_{2, D P}$

$G_{1, D P}$

$G_{2, D P}$

$G_{f, I}$

$G_{f, I I}$

$G_{m}$

$I_{1}$

$J_{2}$

$K_{n}$

$K_{t}$

$Q_{1}$

$Q_{2}$

$Q_{1, D P}$

$W_{p l 1}, W_{p l 2}$
Parameter controlling the shape of the cap surface

Young's modulus of brick

Young's modulus of fill

Young's modulus of spandrel walls

Hyperbolic plastic surface (tension and shear)

Hyperbolic plastic surface (cap model in compression)

First yield surface (Drucker Prager cap model)

Second yield surface (Drucker Prager cap model)

First plastic potential (Drucker Prager cap model)

Second plastic potential (Drucker Prager cap model)

Mode-I (shear) fracture energy

Mode-II (shear) fracture energy

Mortar shear modulus

First invariant of stress tensor

Second deviatoric invariant of stress tensor

Elastic (initial) normal stiffness of interfaces

Elastic (initial) tangential stiffness of interfaces

Plastic potential related to $F_{1}$

Plastic potential related to $F_{2}$

Distinct historical parameters (plastic works)

Latin lower case letters

$\begin{array}{ll}c_{f} & \text { Cohesion of Drucker Prager cap model } \\ c_{w} & \text { Cohesion of spandrel walls } \\ D & \text { Displacement of footing in model of Terzaghi experiment } \\ K & \text { Parameter controlling the shape of the Drucker Prager yield surface } \\ k_{d} & \text { Parameter controlling the shape of the Drucker Prager plastic } \\ Q & \text { potential } \\ R & \text { Distributed load acting of footing in model of Terzaghi experiment } \\ R & \text { Radius of the circular cap in the Drucker Prager cap model }\end{array}$

Greek lower case letters

$\alpha$

$\alpha_{d}$

$\theta$

$v_{b}$

$v_{f}$

$v_{w}$

$\xi$

$\xi_{c}$

$\xi_{\max }$

$\rho$

Parameter controlling the shape of the Drucker Prager yield surface

Parameter controlling the shape of the Drucker Prager plastic potential

Parameters governing the shape of the cap surface

Poisson ratio of brick

Poisson ratio of fill

Poisson ratio of spandrel walls

Parameter related to $I_{1}$

Centre of the circular cap in the Drucker Prager cap model

Maximum allowed value of $\xi$ under isotropic tensile stresses for

Drucker Prager surface

Parameter related to $J_{2}$ 


$\begin{array}{ll}\rho_{f} & \text { Unit weight of fill } \\ \rho_{m} & \text { Unit weight of masonry } \\ \sigma & \text { Normal stress } \\ \sigma_{c} & \text { Compressive strength of masonry } \\ \sigma_{t} & \text { Tensile strength of masonry joint } \\ \tau_{x}, \tau_{y} & \text { Shear stresses } \\ \phi & \text { Friction angle of interfaces } \\ \phi_{w} & \text { Friction angle of spandrel wall } \\ \phi_{w d} & \text { Dilatancy angle of spandrel wall } \\ \varphi_{f} & \text { Angle of friction of Drucker Prager cap model } \\ \varphi_{d} & \text { Dilatancy angle of Drucker Prager cap model } \\ \chi & \text { Cap value of } \xi \text { under isotropic tensile stresses } \\ \psi & \text { Dilatancy angle of interfaces }\end{array}$


Table 1: Principal dimensions for Bridge 3-1 and Bridge 3-3

\begin{tabular}{|l|l|l|l|l|l|}
\hline \multirow{2}{*}{ Arch } & Span $(\mathbf{m m})$ & Rise $(\mathbf{m m})$ & $\begin{array}{l}\text { Ring thickness } \\
(\mathbf{m m})\end{array}$ & Width $(\mathbf{m m})$ & $\begin{array}{l}\text { n. of } \\
\text { bricks }\end{array}$ \\
\cline { 2 - 5 } & 3000 & 750 & 215 & $\begin{array}{l}2880(\text { Bridge 3-1) } \\
3540(\text { Bridge 3-3) }\end{array}$ & 48 \\
\hline \multirow{2}{*}{ Backfill } & Depth at crown $(\mathbf{m m})$ & Width $(\mathbf{m m})$ & Length $(\mathbf{m m})$ & \\
\cline { 2 - 6 } & 300 & 2880 & $2460 \times 2+3000$ & \\
\hline \multirow{2}{*}{$\begin{array}{l}\text { Spandrel walls } \\
\text { (Bridge 3-3) }\end{array}$} & Depth at crown $(\mathbf{m m})$ & Width $(\mathbf{m m})$ & Length $(\mathbf{m m})$ & \\
\cline { 2 - 6 } & 300 & 330 & $2460 \times 2+3000$ & \\
\hline
\end{tabular}

Table 2: Mechanical properties for nonlinear interfaces

\begin{tabular}{|c|c|c|}
\hline & Surface $F_{1}$ & Surface $Q_{1}$ \\
\hline \multirow{5}{*}{$\begin{array}{l}\text { Mortar-brick } \\
\text { interface }\end{array}$} & $C=0.29 \mathrm{~N} / \mathrm{mm}^{2}$ & $C=0.29 \mathrm{~N} / \mathrm{mm}^{2}$ \\
\hline & $\sigma_{\mathrm{t}}=0.20 \mathrm{~N} / \mathrm{mm}^{2}$ & $\sigma_{\mathrm{t}}=0.20 \mathrm{~N} / \mathrm{mm}^{2}$ \\
\hline & $\tan \phi=0.50$ & $\tan \psi=0.00$ \\
\hline & $G_{f l}=0.02 \mathrm{~N} / \mathrm{mm}$ & $G_{f l}=0.02 \mathrm{~N} / \mathrm{mm}$ \\
\hline & $G_{f 2}=0.125 \mathrm{~N} / \mathrm{mm}$ & $G_{f 2}=0.125 \mathrm{~N} / \mathrm{mm}$ \\
\hline \multirow{5}{*}{$\begin{array}{c}\text { Arch-backfill } \\
\text { interface }\end{array}$} & $C=0.0029 \mathrm{~N} / \mathrm{mm}^{2}$ & $C=0.0029 \mathrm{~N} / \mathrm{mm}^{2}$ \\
\hline & $\sigma_{\mathrm{t}}=0.0020 \mathrm{~N} / \mathrm{mm}^{2}$ & $\sigma_{\mathrm{t}}=0.0020 \mathrm{~N} / \mathrm{mm}^{2}$ \\
\hline & $\tan \phi=0.60$ & $\tan \psi=0.60$ \\
\hline & $G_{f l}=1000 \mathrm{~N} / \mathrm{mm}$ & $G_{f l}=1000 \mathrm{~N} / \mathrm{mm}$ \\
\hline & $G_{f 2}=1000 \mathrm{~N} / \mathrm{mm}$ & $G_{f 2}=1000 \mathrm{~N} / \mathrm{mm}$ \\
\hline \multirow{5}{*}{$\begin{array}{l}\text { Brick-brick } \\
\text { interface }\end{array}$} & $C=2.80 \mathrm{~N} / \mathrm{mm}^{2}$ & $C=2.80 \mathrm{~N} / \mathrm{mm}^{2}$ \\
\hline & $\sigma_{\mathrm{t}}=2.00 \mathrm{~N} / \mathrm{mm}^{2}$ & $\sigma_{\mathrm{t}}=2.00 \mathrm{~N} / \mathrm{mm}^{2}$ \\
\hline & $\tan \phi=1.00$ & $\tan \psi=1.00$ \\
\hline & $G_{f l}=0.08 \mathrm{~N} / \mathrm{mm}$ & $G_{f l}=0.08 \mathrm{~N} / \mathrm{mm}$ \\
\hline & $G_{f 2}=0.50 \mathrm{~N} / \mathrm{mm}$ & $G_{f 2}=0.50 \mathrm{~N} / \mathrm{mm}$ \\
\hline
\end{tabular}




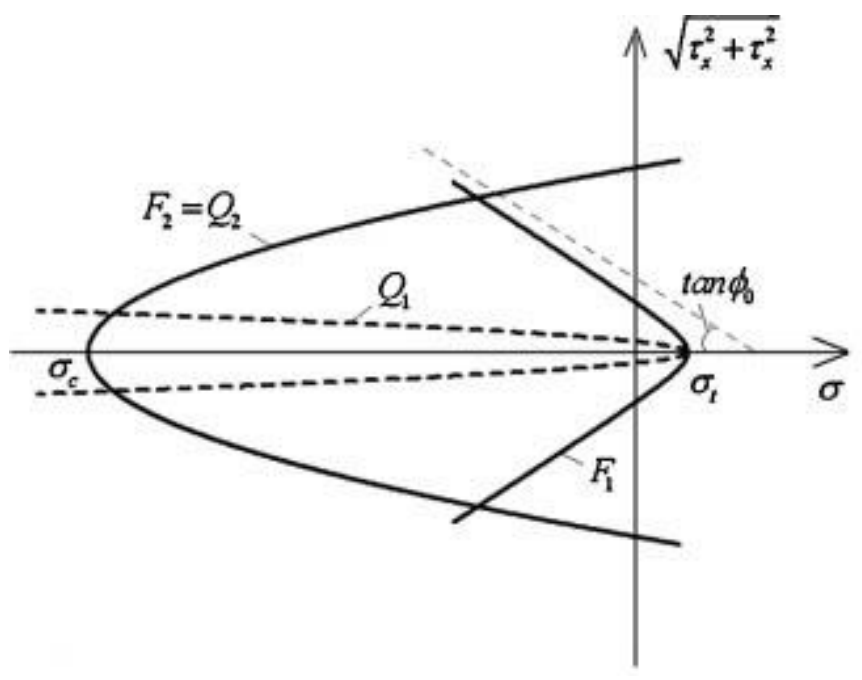

(a)

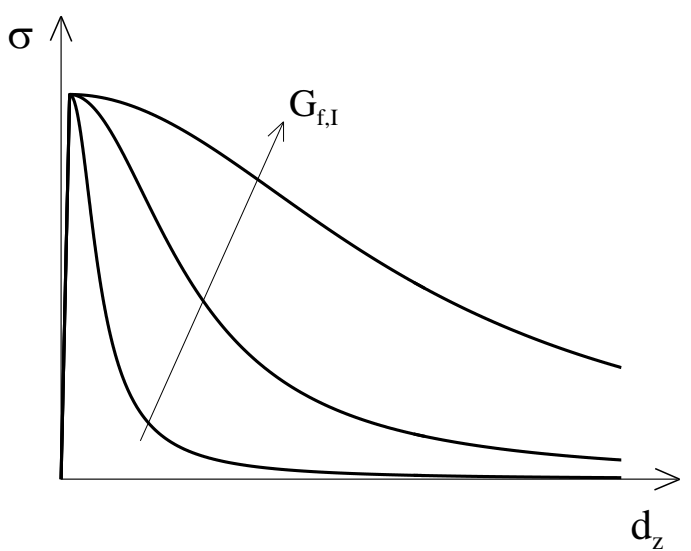

(b)

Figure 1: Material description for nonlinear interface elements: (a) yield functions and plastic potentials, (b) traction-separation curves in tension [11] 


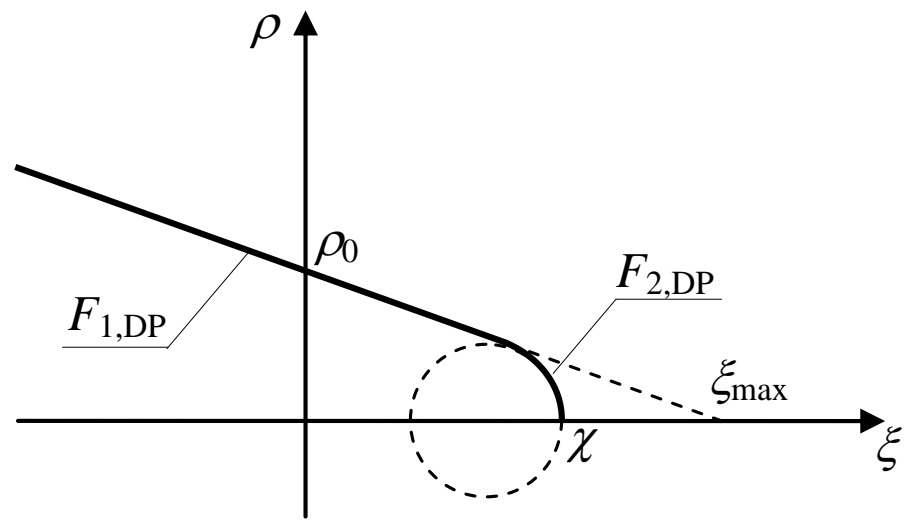

(a)

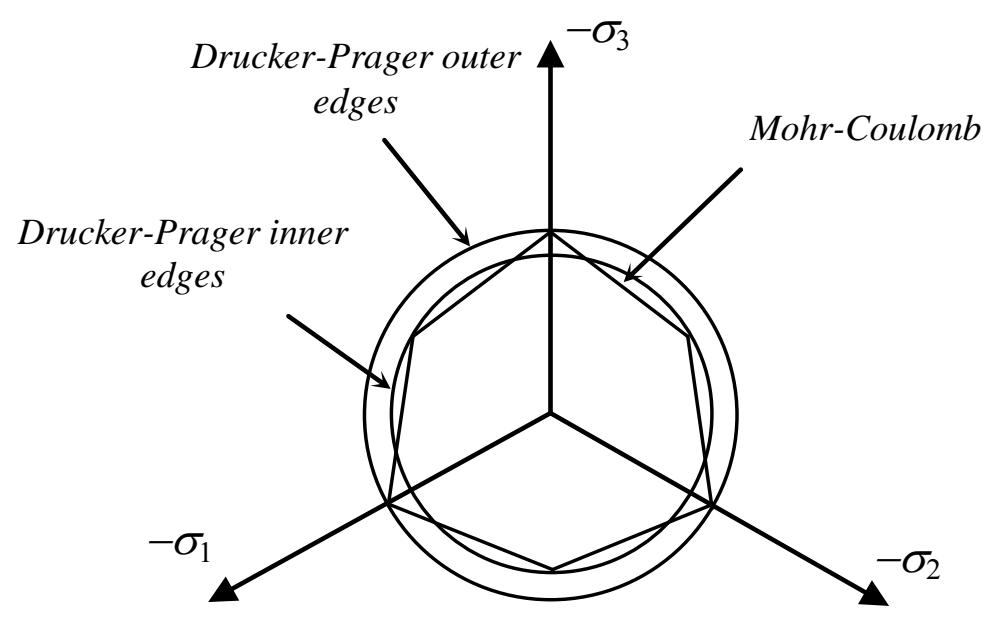

(b)

Figure 2: (a) Representation of the multi-yield surface in the meridional plane; (b) Deviatoric-plane section of the Mohr-Coulomb surface and the corresponding DruckerPrager approximations. 


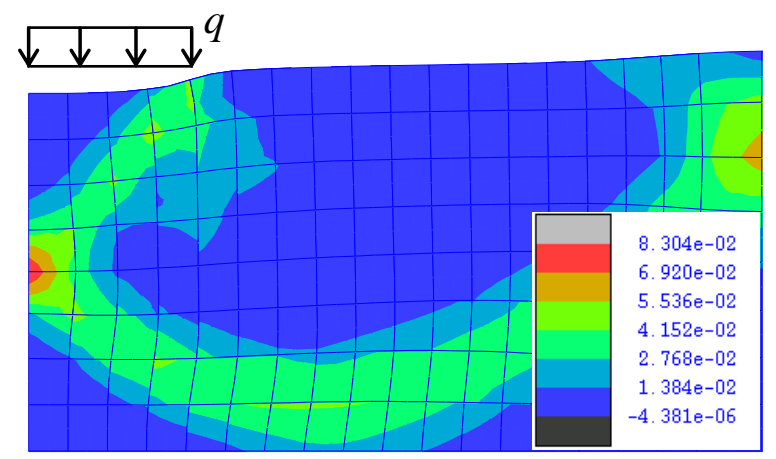

(a)

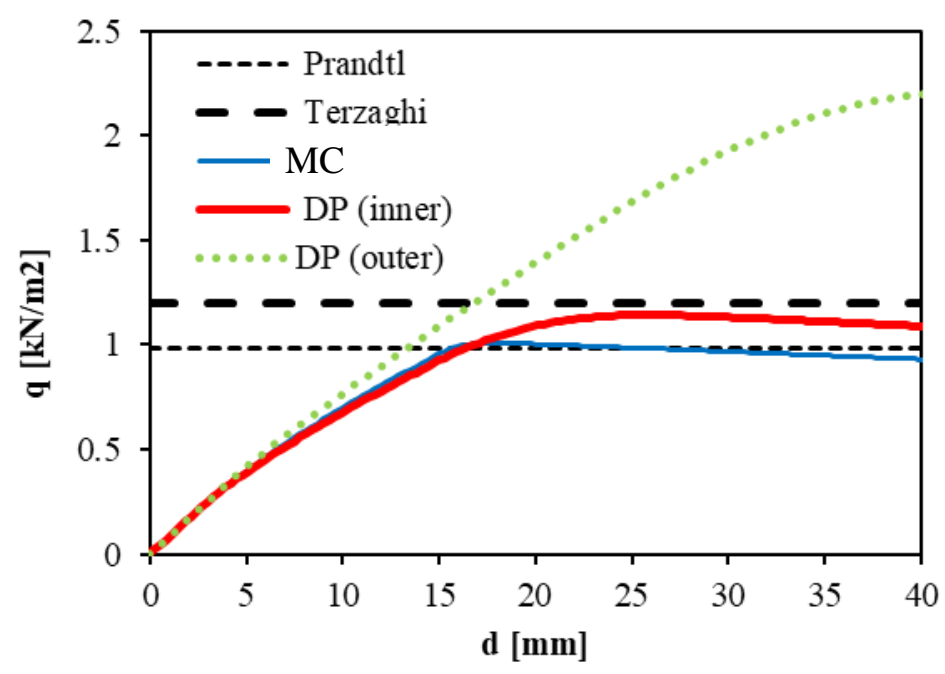

(b)

Figure 3: (a) Equivalent von Mises plastic deformations for a maximum displacement $d=40$ $\mathrm{mm}$ obtained by considering the DP model fitted to the MC inner edges, (b) numerical loaddisplacement curves and analytical estimates of the load-bearing capacity.

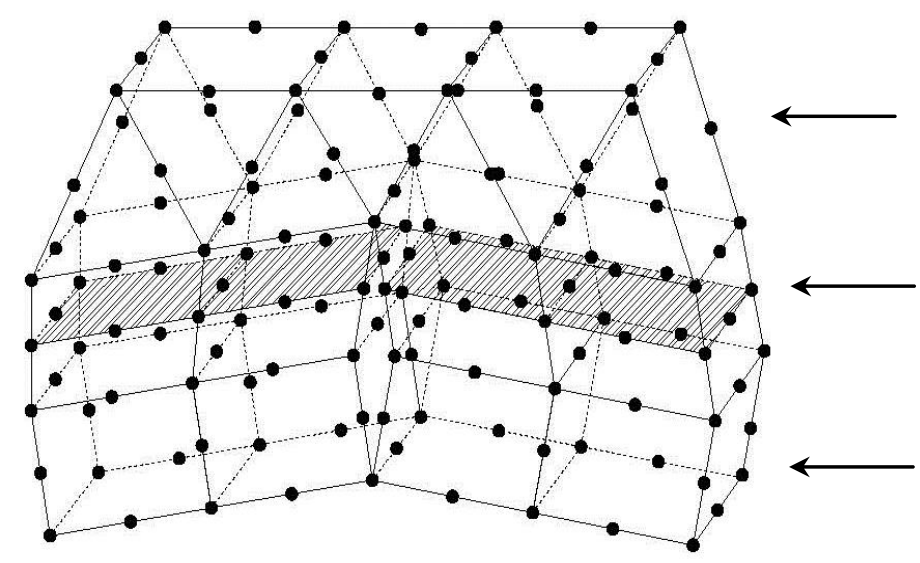

Backfill

(15-noded wedge elements)

Physical interface between arch and backfill

(16-noded interface elements)

Masonry arch

(20-noded brick +

16-noded interface elements)

Figure 4: Modelling arch-fill interaction using 2D nonlinear interface elements 


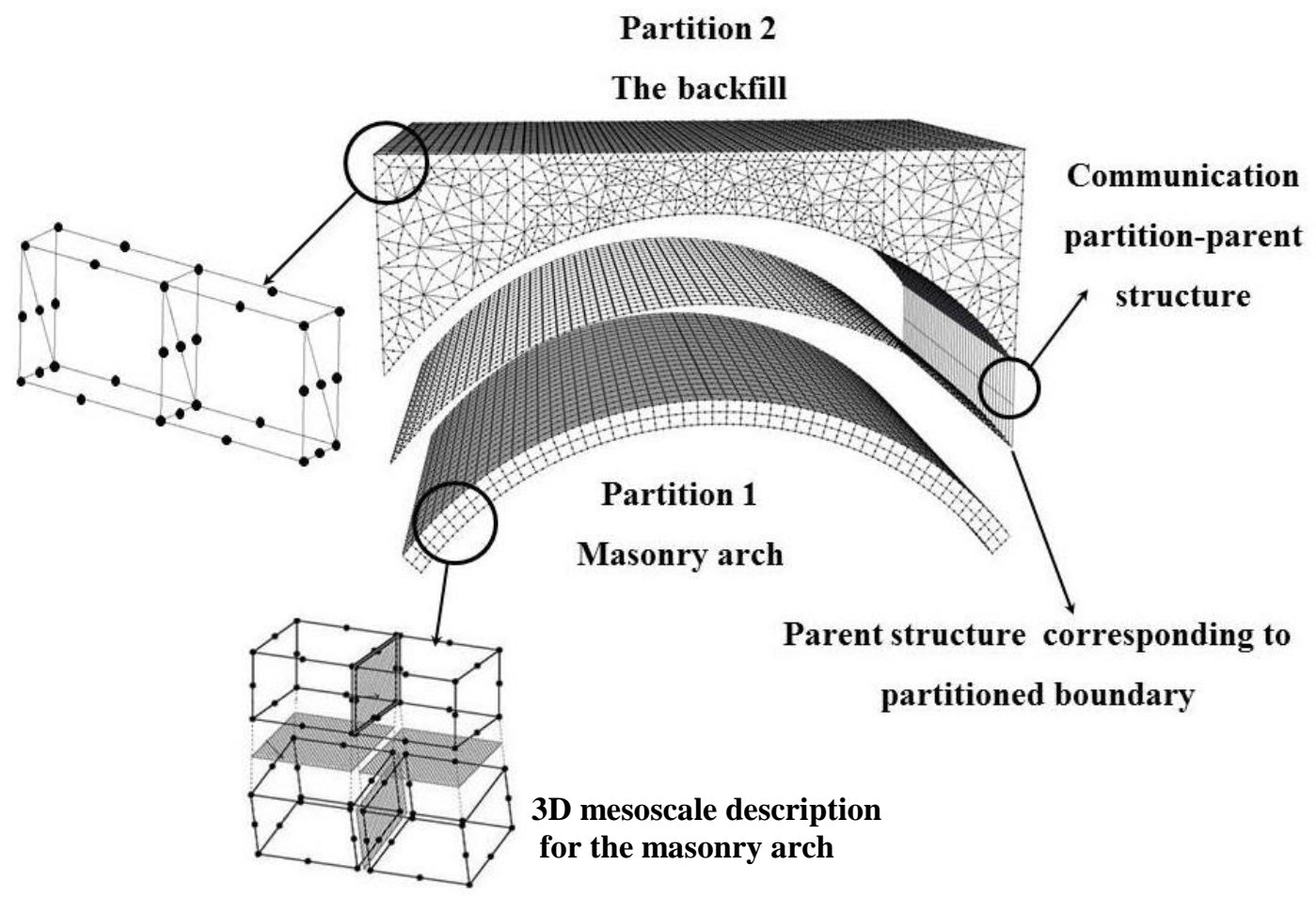

Figure 5: Domain partitioned modelling approach for masonry arch bridges

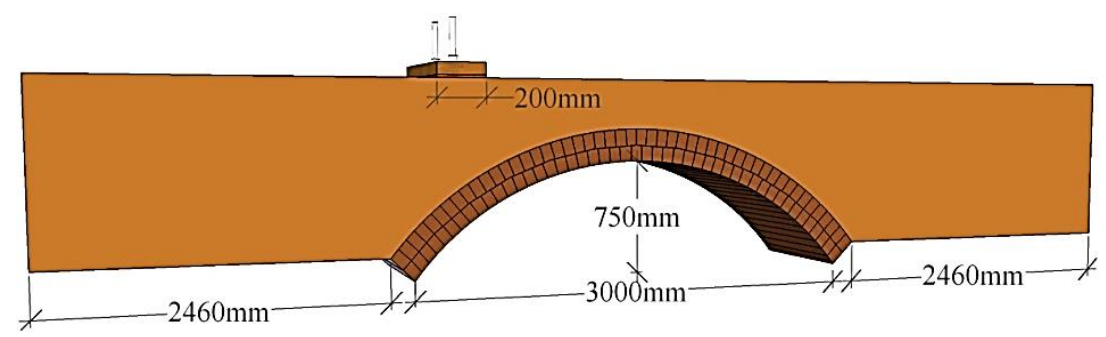

Figure 6: Geometric characteristics and loading arrangement for Bridge 3-1

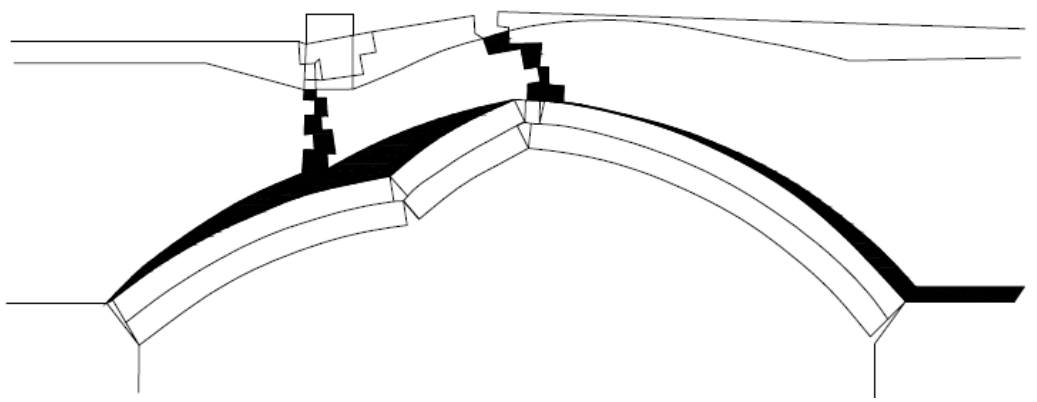

Figure 7: Failure mechanism of Bridge 3-1 [17] 


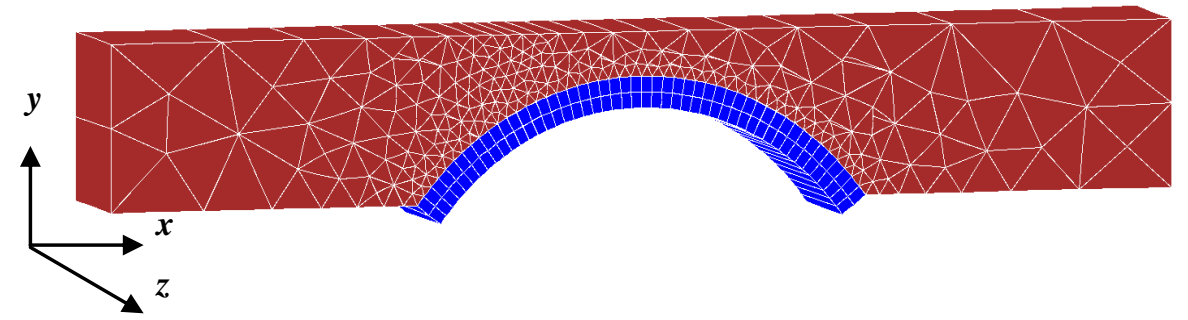

Figure 8: FE mesh for Bridge 3-1

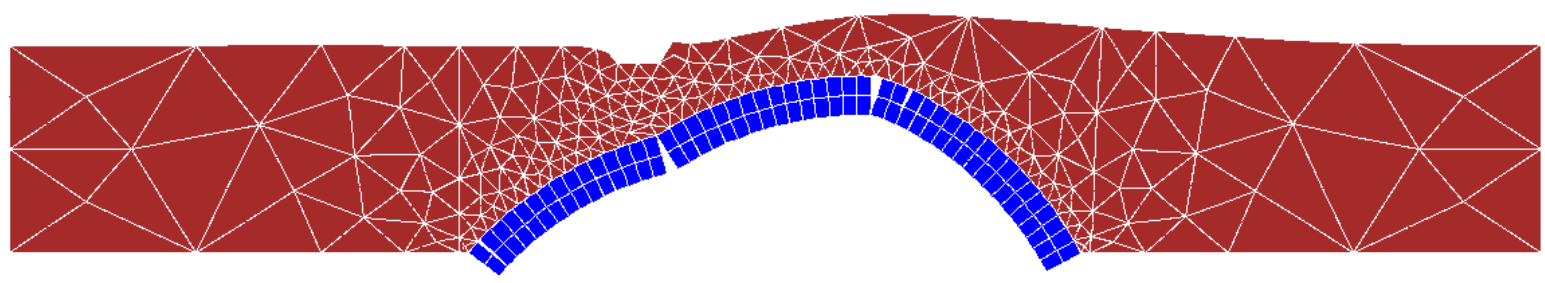

Figure 9: Deformed shape at the last step of the analysis for Bridge 3-1

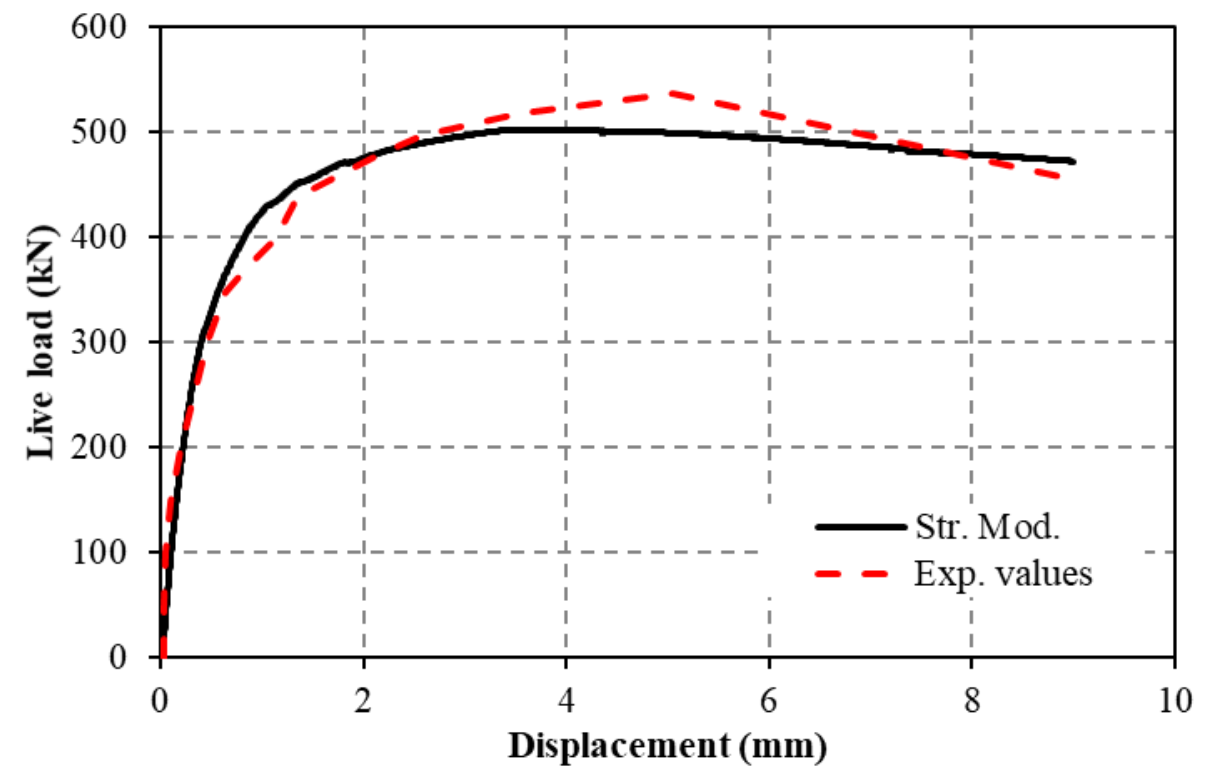

Figure 10: Experimental-numerical comparison for Bridge 3-1 


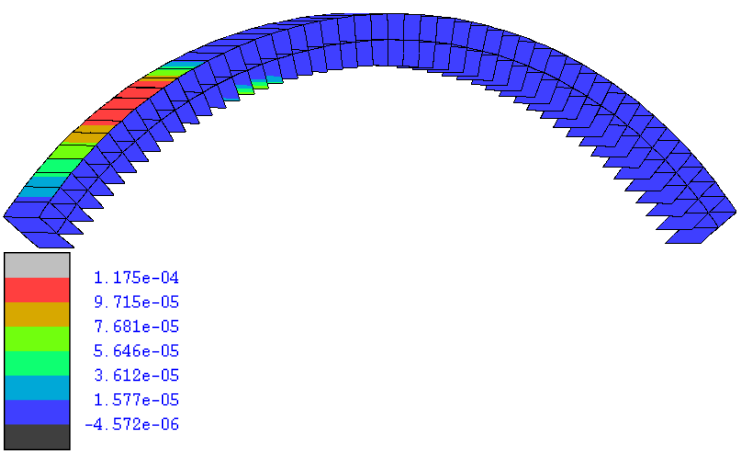

(a) $1^{\text {st }}$ radial crack $P=80 \mathrm{kN}$

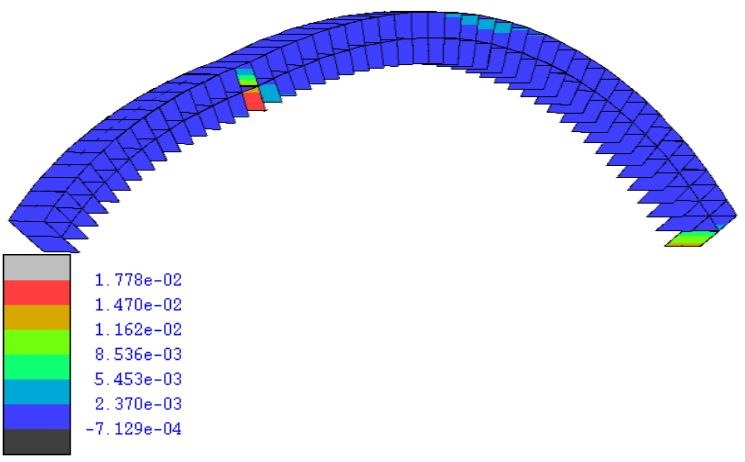

(c) $3^{\text {rd }}$ radial crack $P=372 \mathrm{kN}$

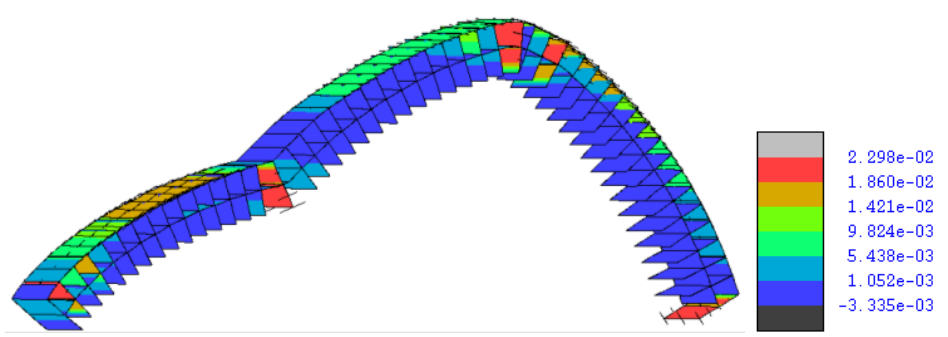

(e) Final step

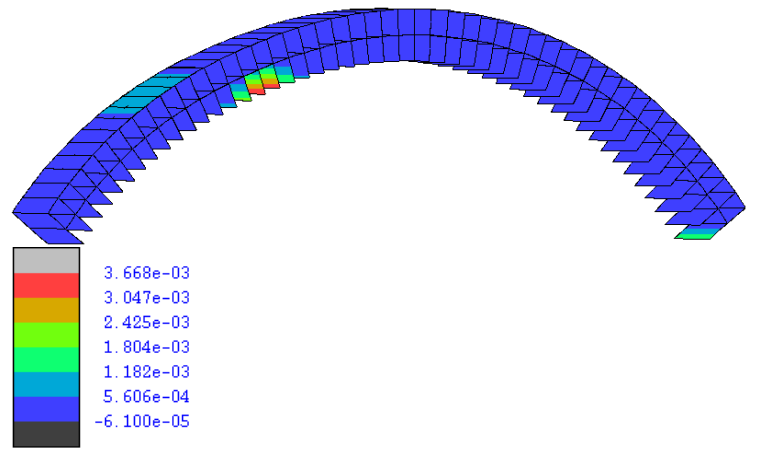

(b) $2^{\text {nd }}$ radial crack $P=240 \mathrm{kN}$

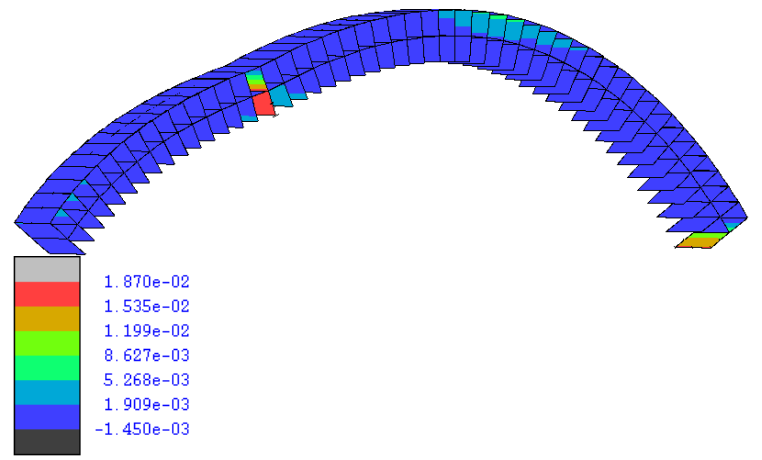

(d) $4^{\text {th }}$ radial crack $P=402 \mathrm{kN}$

Figure 11: Plastic work $W_{p l l}(\mathrm{~N} / \mathrm{mm})$ contours at (a) $1^{\text {st }}$ radial crack $P=80 \mathrm{kN}$, (b) $2^{\text {nd }}$ radial crack $P=240 \mathrm{kN}$, (c) $3^{\text {rd }}$ radial crack $P=372 \mathrm{kN}$, (d) $4^{\text {th }}$ radial crack $P=402 \mathrm{kN}$ and (e) at the final step of analysis 

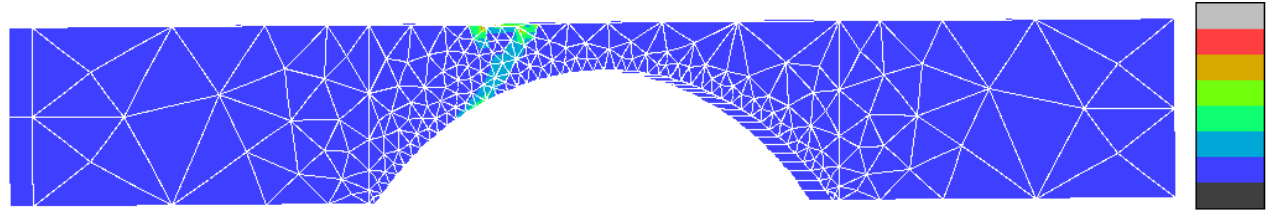

1. $239 \mathrm{e}-03$ 1. $032 \mathrm{e}-03$ 8. $258 \mathrm{e}-04$

4. $129 \mathrm{e}-04$

2. $065 e-04$

(a) $P=80 \mathrm{kN}$
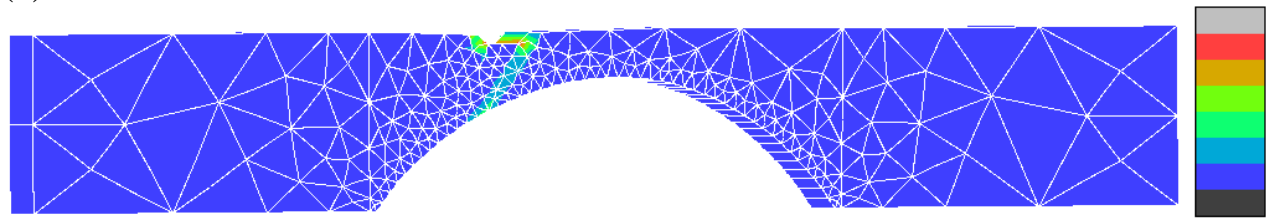

5. $684 \mathrm{e}-03$

4. $736 \mathrm{e}-03$

3. $789 e-03$

2. $842 \mathrm{e}-03$

1. $895 \mathrm{e}-03$

9. $473 e-04$

$0.000 e+00$

(b) $P=240 \mathrm{kN}$
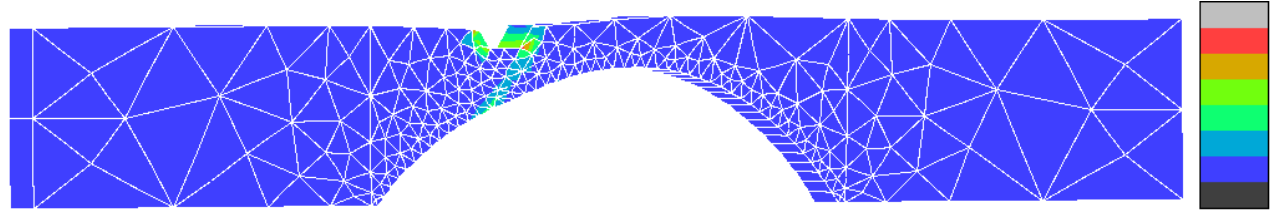

1. $169 \mathrm{e}-02$

9. $742 \mathrm{e}-03$

7. $793 \mathrm{e}-03$

5. $845 \mathrm{e}-03$

3. $897 \mathrm{e}-03$

1. $948 \mathrm{e}-03$

(c) $P=372 \mathrm{kN}$
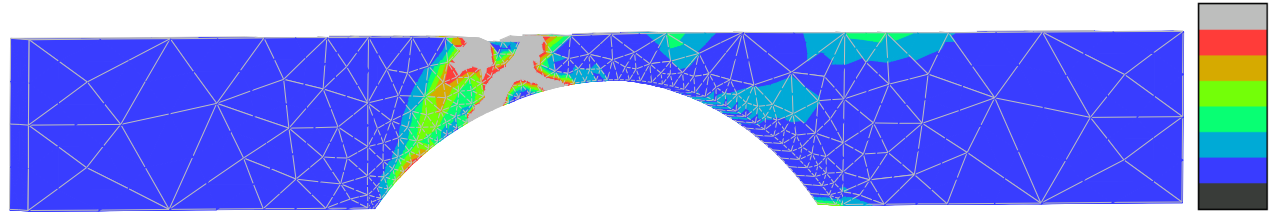

1. $500 e-03$

1. $250 \mathrm{e}-03$

1. $000 \mathrm{e}-03$

$7.500 \mathrm{e}-04$

5. $000 \mathrm{e}-04$

2. $500 \mathrm{e}-04$

(d) $P=402 \mathrm{kN}$

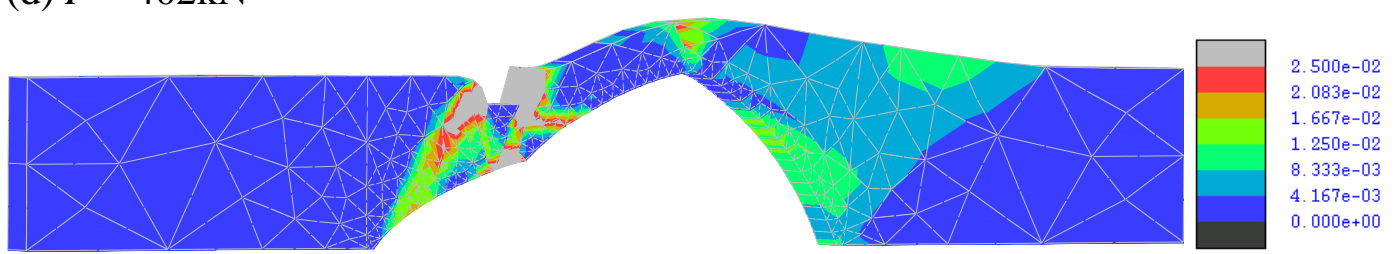

(e) Final step

Figure 12: Equivalent von Mises plastic deformations in the backfill at (a) $P=80 \mathrm{kN}$, (b) $P=240 \mathrm{kN}$, (c) $P=372 \mathrm{kN}$, (d) $P=402 \mathrm{kN}$ and (e) at the final step of analysis 


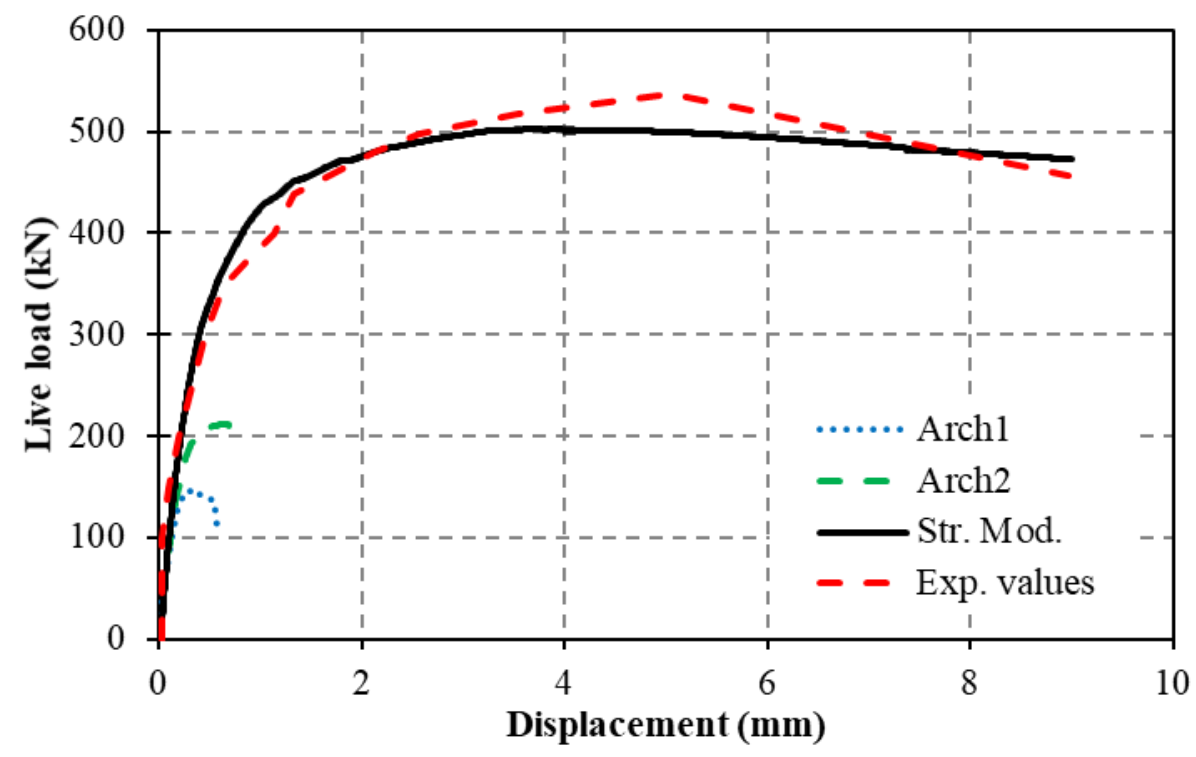

Figure 13: Numerical comparisons among the strip-model and models allowing only for the arch contribution

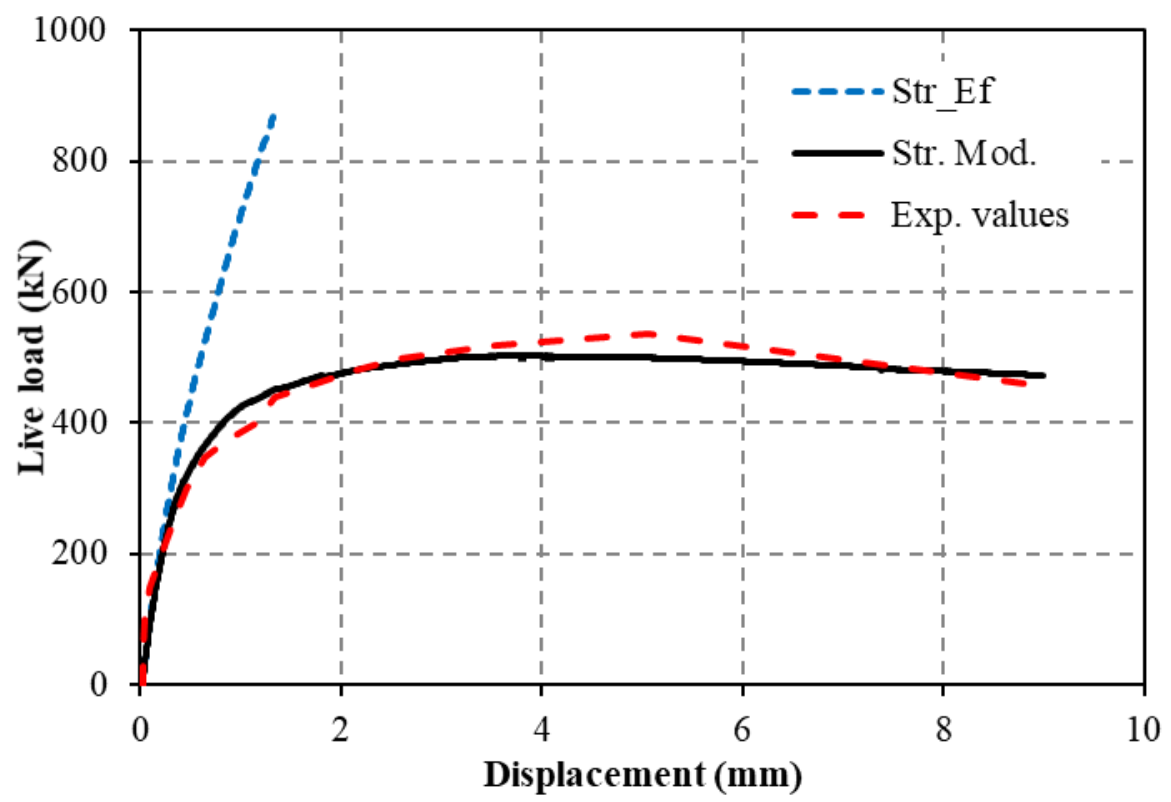

Figure 14: Numerical results considering a linear elastic backfill domain (Str_Ef). 


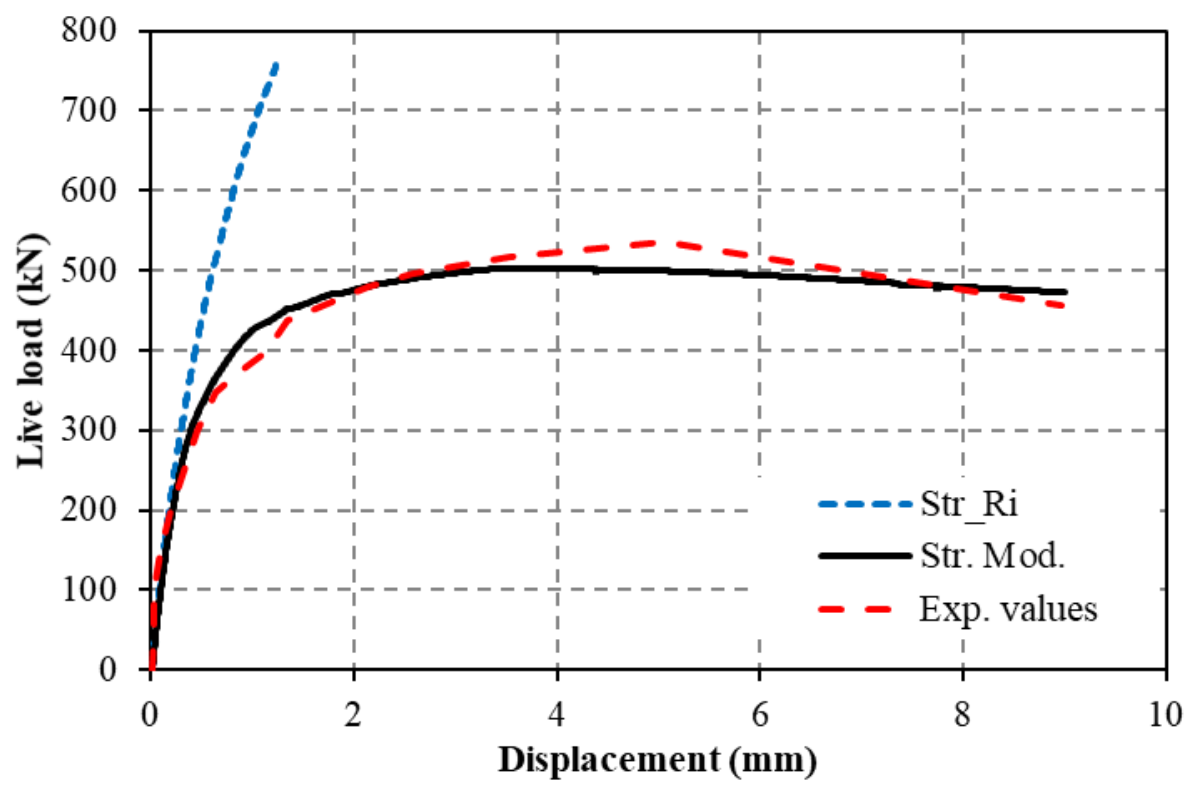

Figure 15: Numerical results considering rigid interfaces (Str_Ri) between the arch and the backfill.

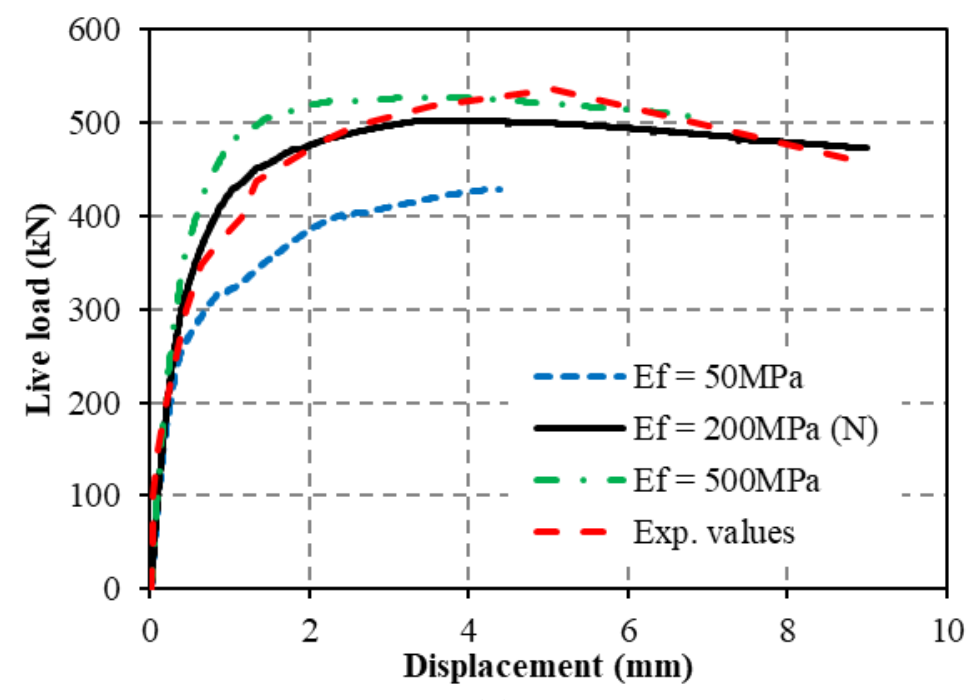

(a)

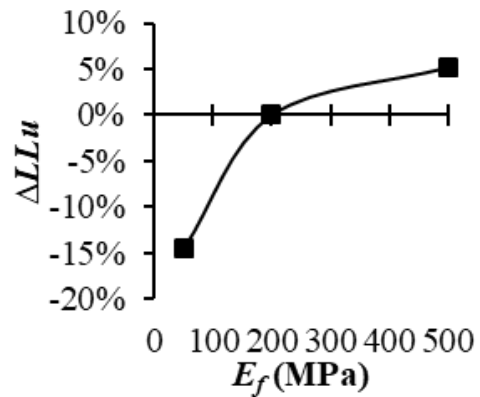

(b)

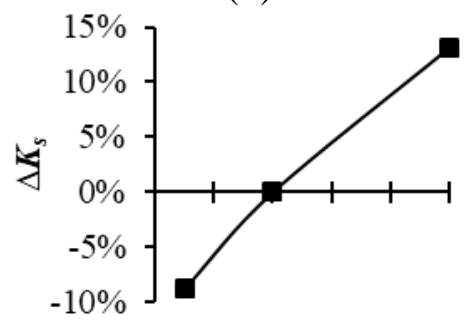

$0 \quad 100200300400500$ $E_{f}(\mathrm{MPa})$

(c)

Figure 16: Influence of the backfill Young's modulus $\left(E_{f}\right)$ on the (a) bridge response, (b) ultimate load, and (b) initial stiffness 


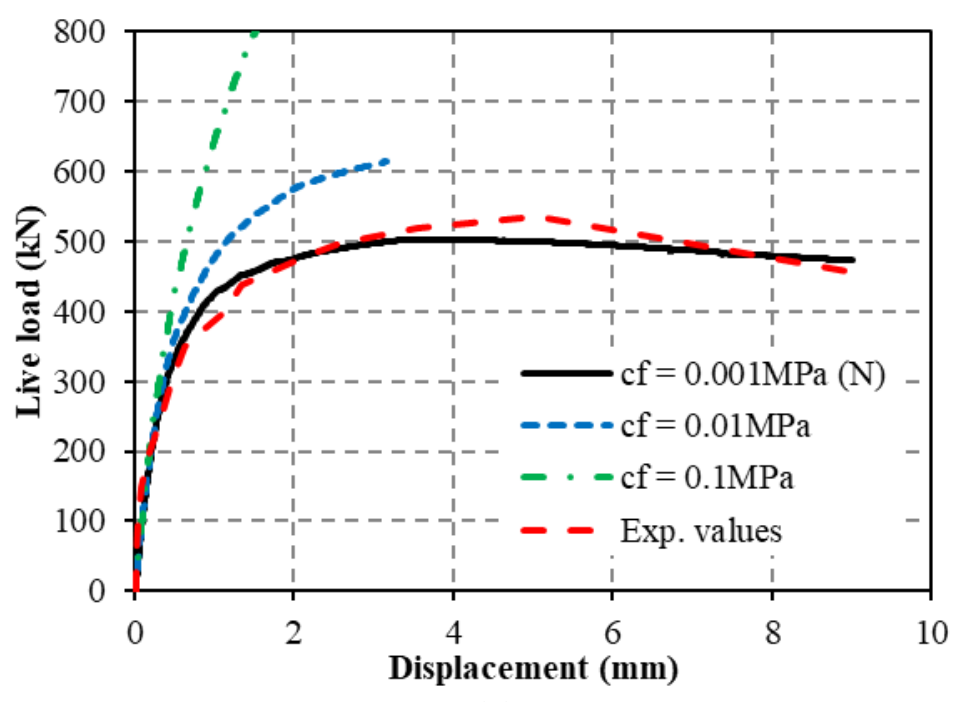

(a)

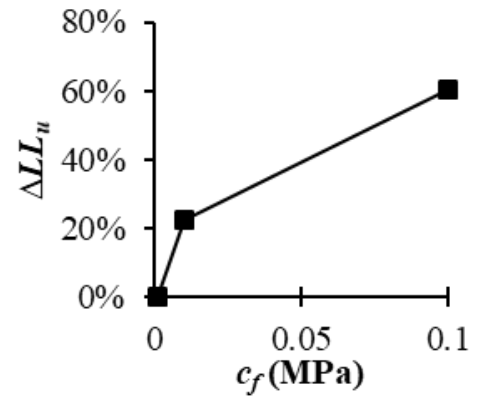

(b)

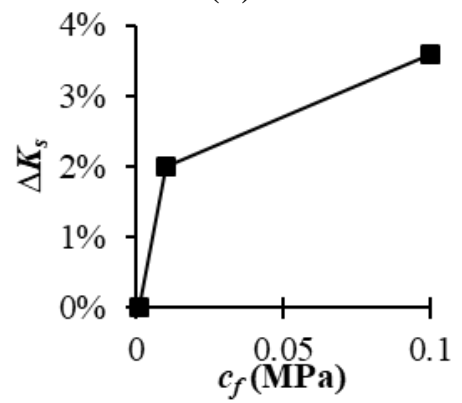

(c)

Figure 17: Influence of the backfill cohesion $\left(c_{f}\right)$ on the (a) bridge response, (b) ultimate load, and (c) secant stiffness

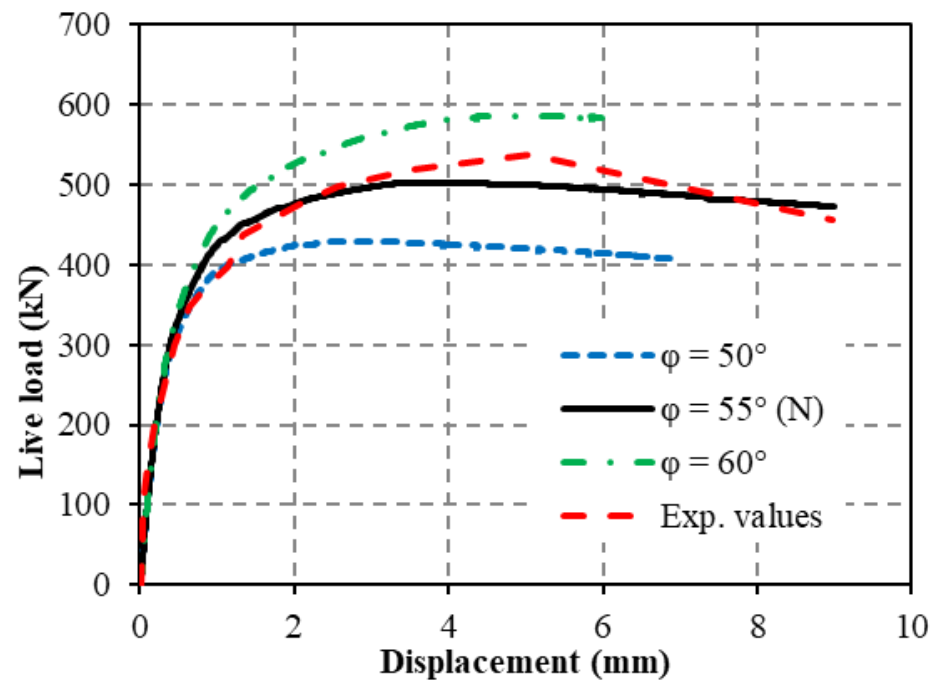

(a)

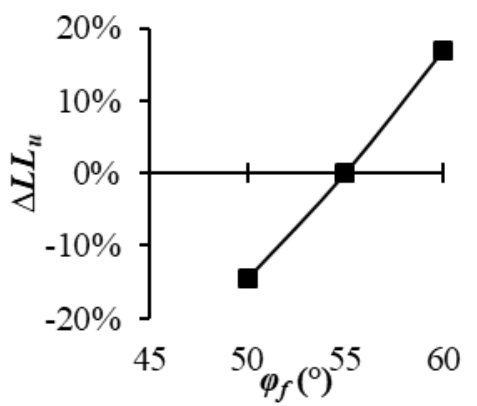

(b)

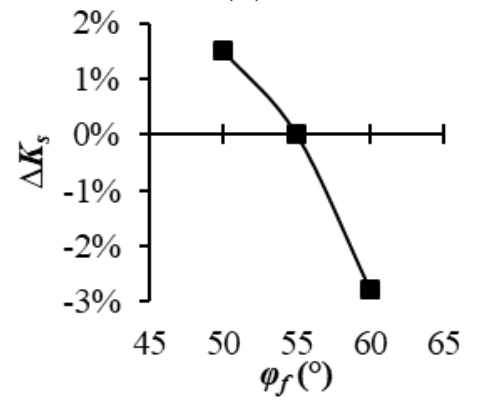

(c)

Figure 18: Influence of the backfill friction angle $\left(\varphi_{f}\right)$ on the (a) bridge response, (b) ultimate load, and (c) secant stiffness 


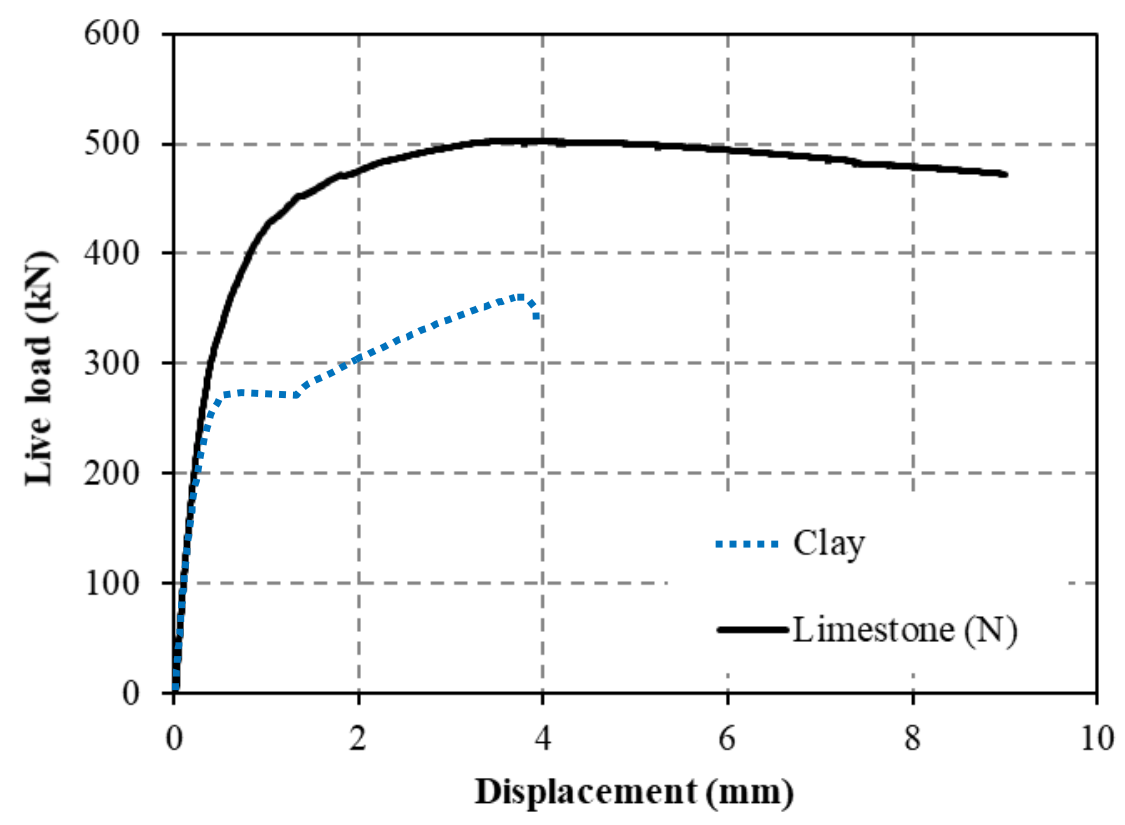

Figure 19: Load displacement curves for different types of backfill
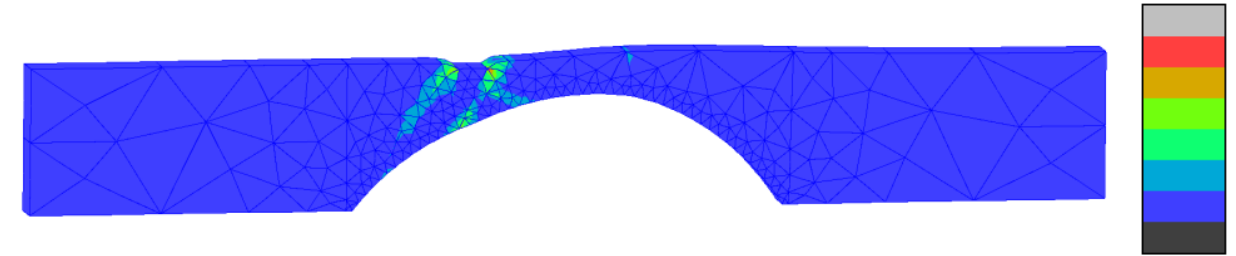

4. $000 \mathrm{e}-02$

3. $333 \mathrm{e}-02$

2. $667 \mathrm{e}-02$

2. $000 \mathrm{e}-02$

1. $333 \mathrm{e}-02$

6. $667 e-03$

$0.000 e+00$

(a)
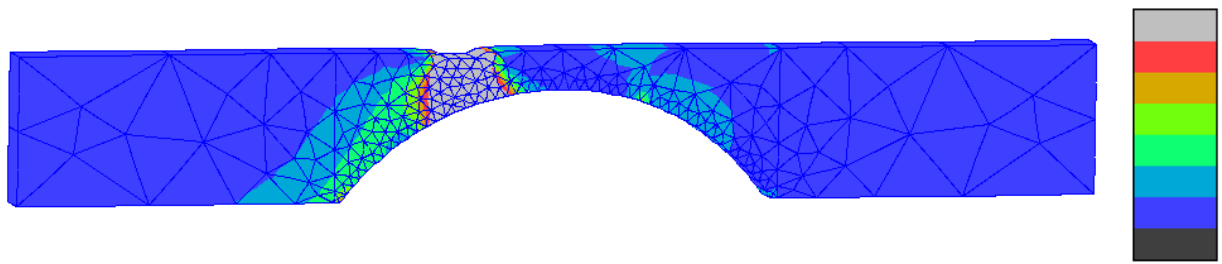

1. $500 \mathrm{e}-01$

1. $250 \mathrm{e}-01$

1. $000 \mathrm{e}-01$

7. $500 \mathrm{e}-02$

5. $000 \mathrm{e}-02$

2. $500 \mathrm{e}-02$

$0.000 \mathrm{e}+00$

(b)

Figure 20: Equivalent von Mises plastic deformations for the (a) limestone and (b) clay backfill at peak load 

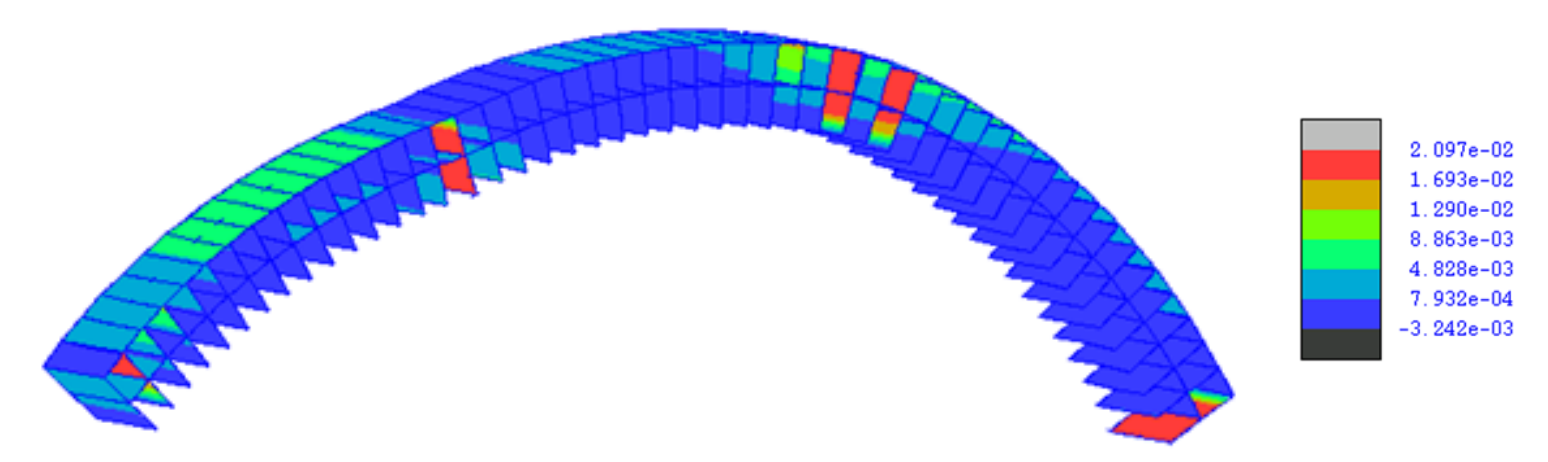

(a)

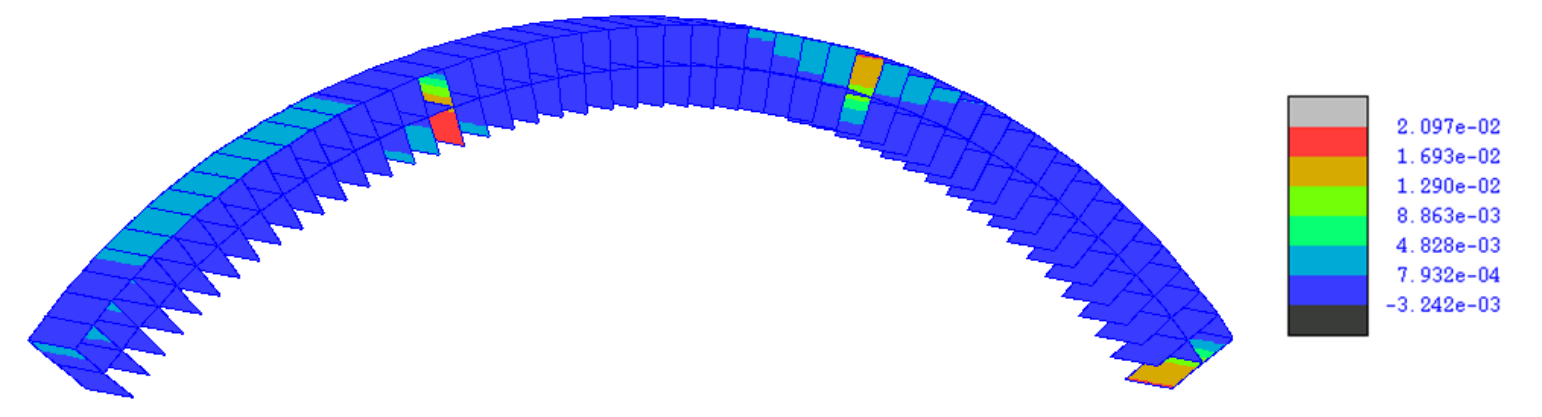

(b)

Figure 21: Plastic work $W_{p l 1}(\mathrm{~N} / \mathrm{mm})$ in the interface elements for (a) limestone and (b) clay backfill at peak load

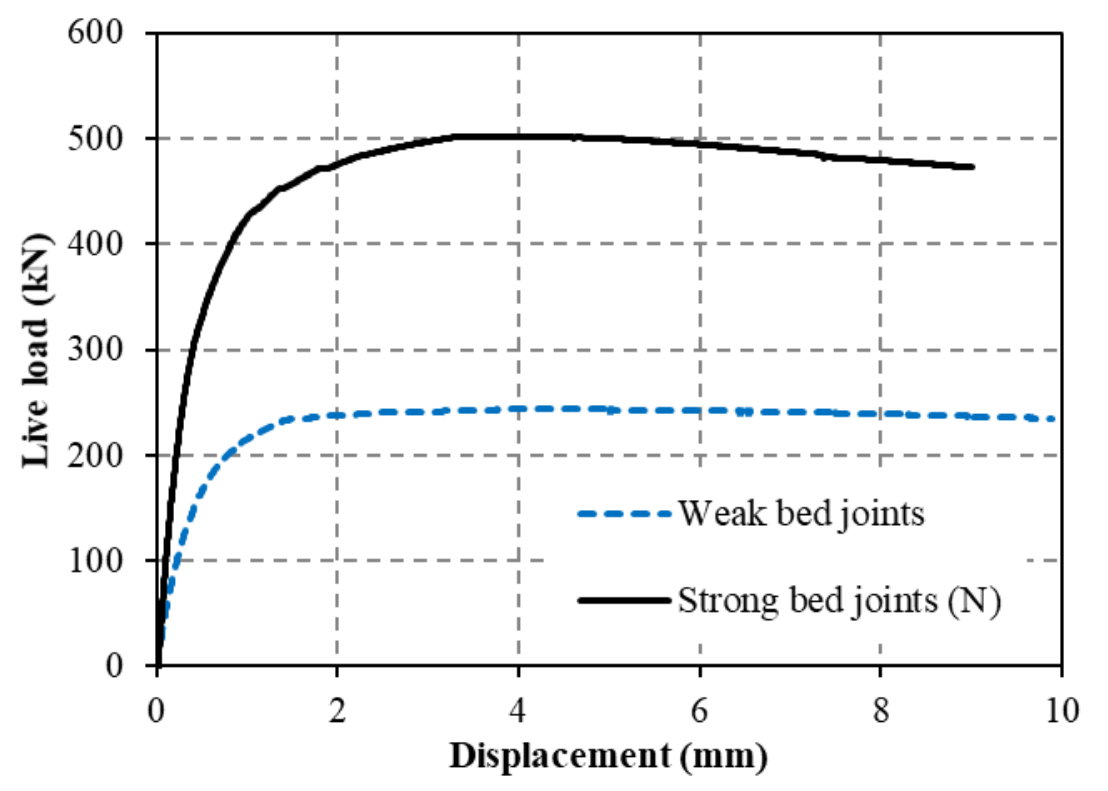

Figure 22: Influence of defects in the brickwork on the load-displacement response 


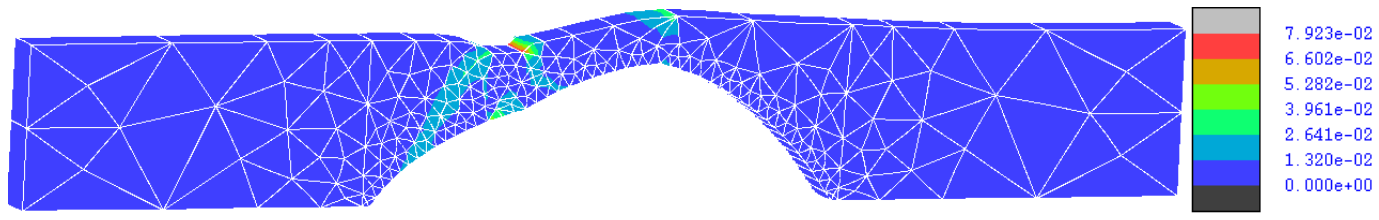

(a)

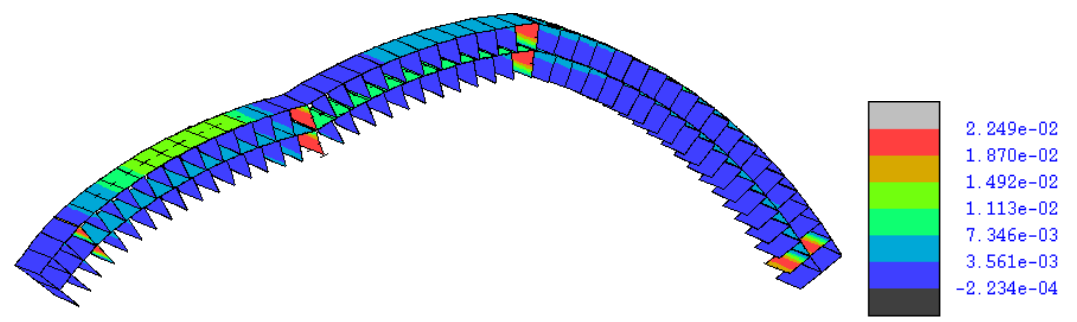

(b)

Figure 23: Contours at final step of the analysis for (a) Equivalent von Mises plastic deformations in the backfill; (b) interface plastic work $W_{p l l}(\mathrm{~N} / \mathrm{mm})$ in the arch barrel for a masonry bridge with defects in the brickwork

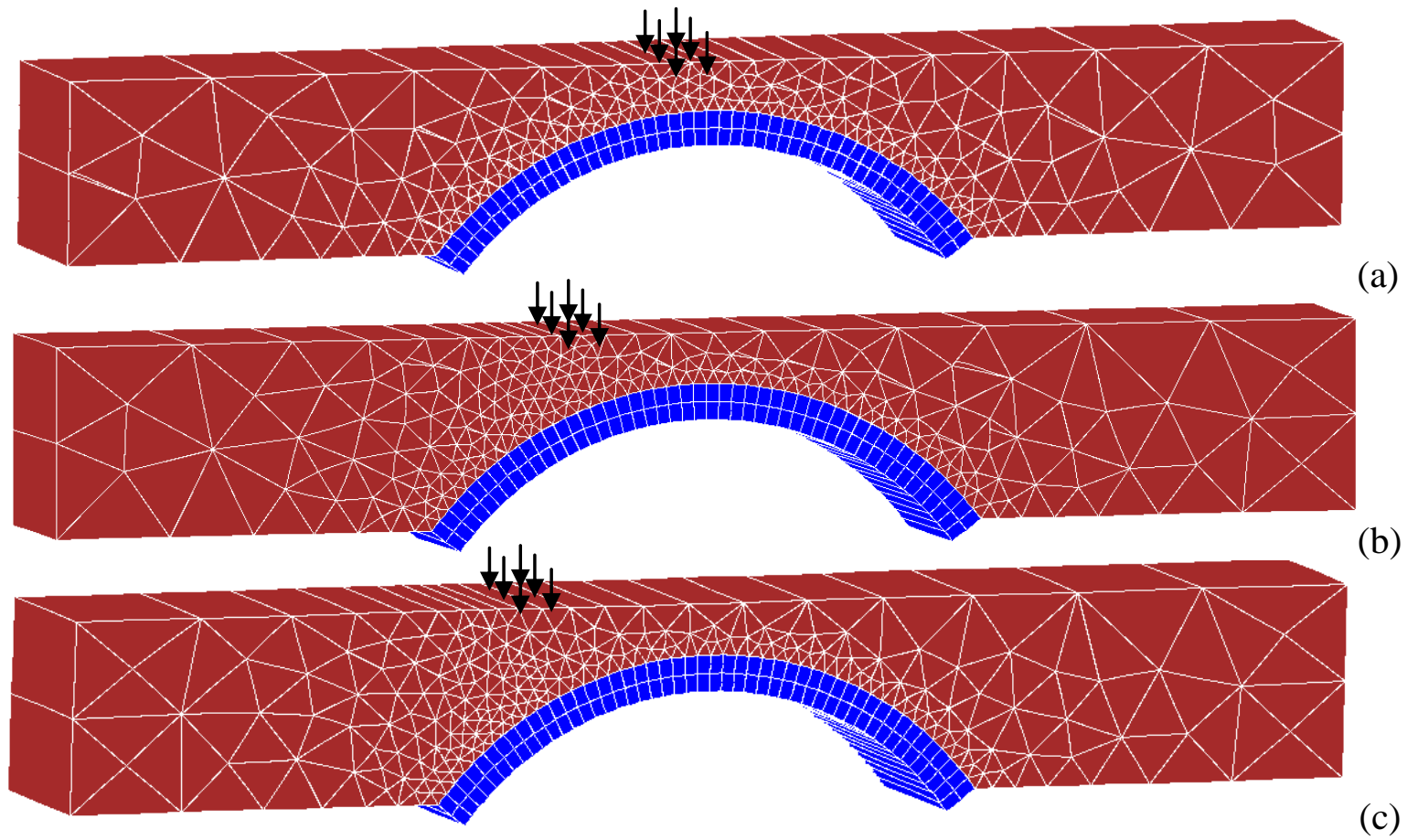

Figure 24: FE models with different loading positions (a) 1/2 span, (b) at 1/4 span, and (c) $1 / 8$ span 


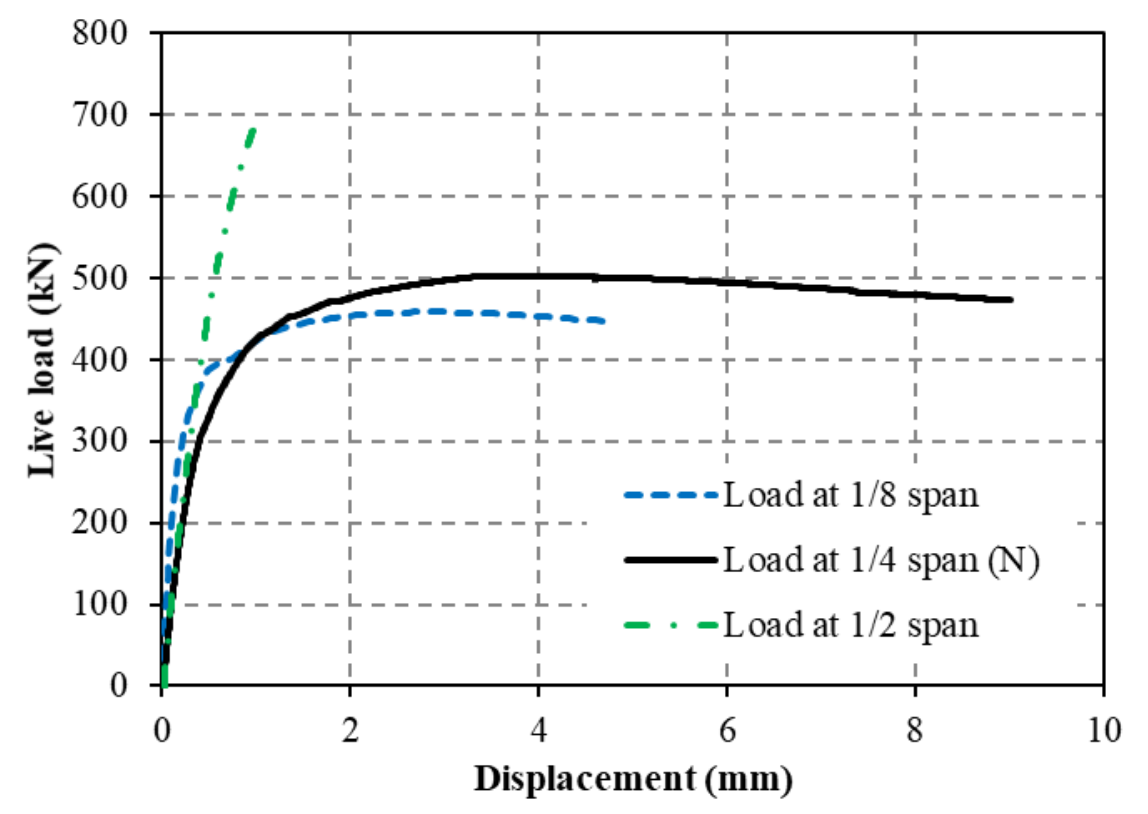

Figure 25: Influence of loading position on the bridge response

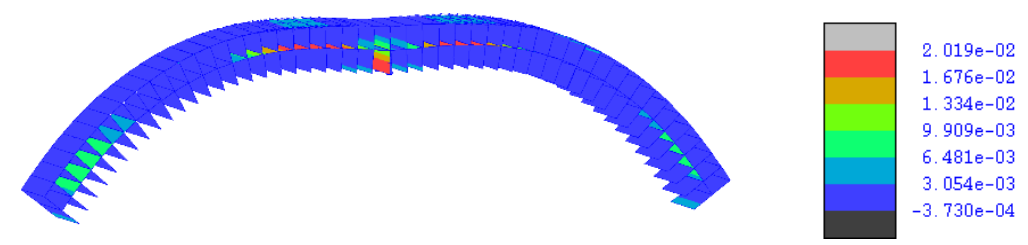

(a)

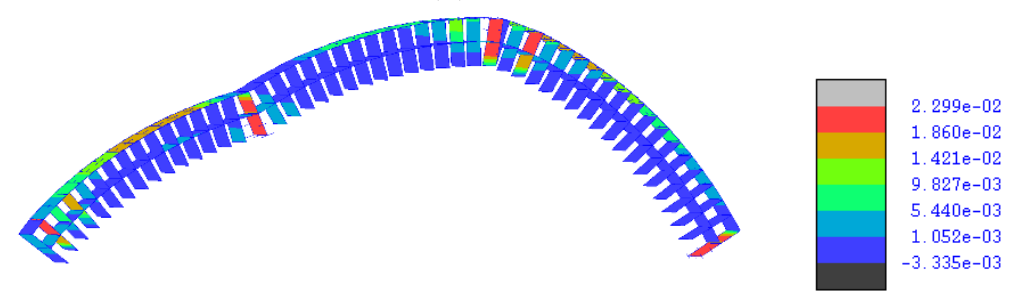

(b)

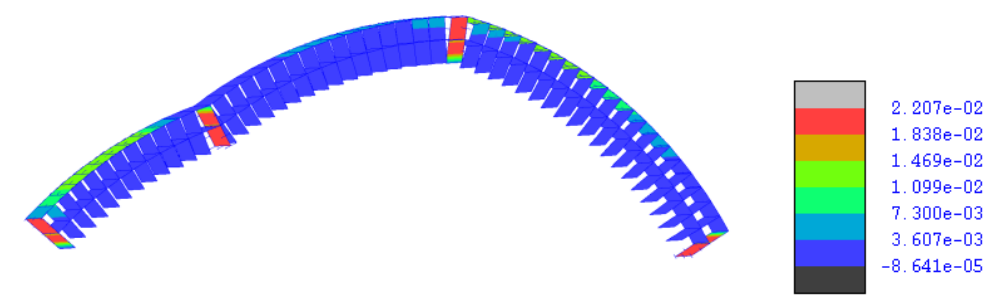

$(\mathrm{N} / \mathrm{mm})$

(c)

Figure 26: Interface plastic work $W_{p l l}(\mathrm{~N} / \mathrm{mm})$ contour for different loading positions (a) $1 / 2$ span, (b) at 1/4 span, and (c) 1/8 span 


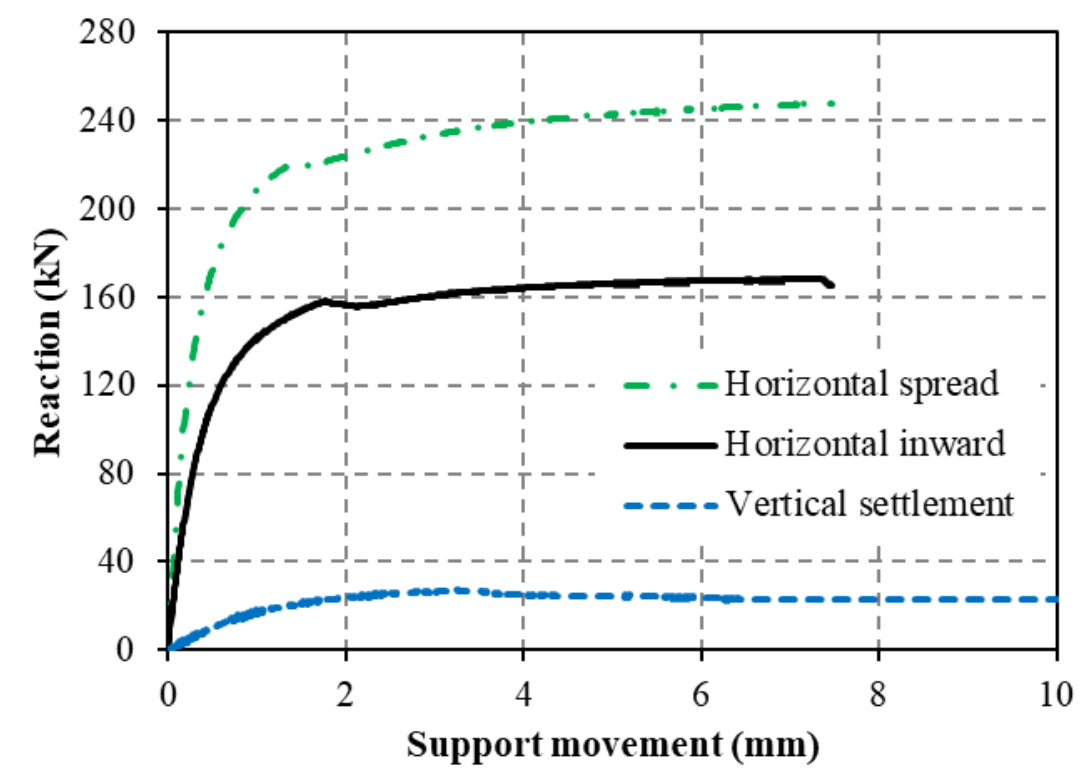

Figure 27: Influence of support movements on the bridge response
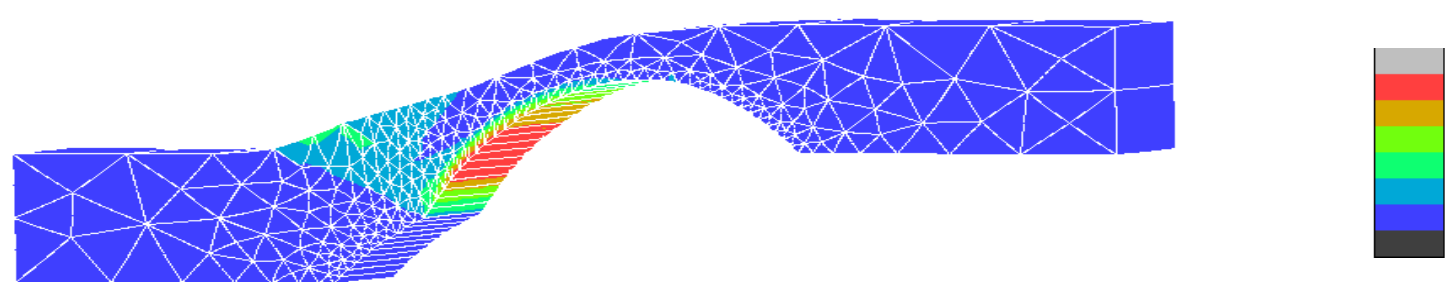

(a) Vertical settlement of support
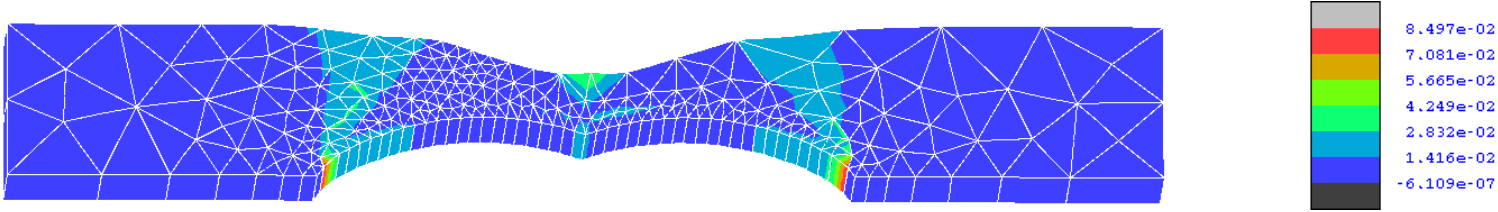

(b) Horizontal spread of support
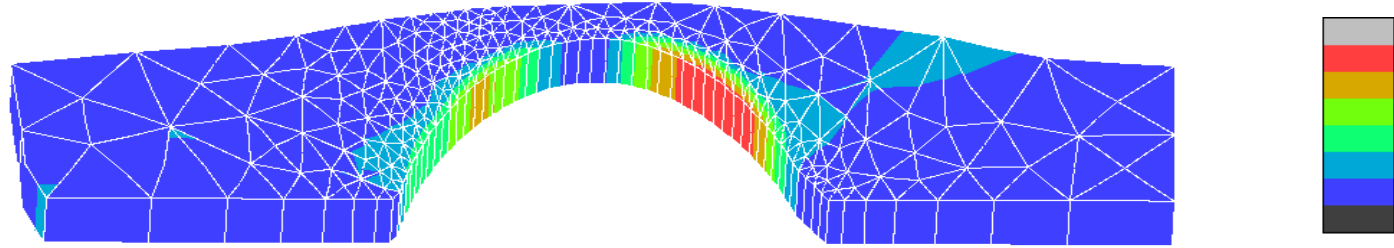

(c) Horizontal inward of support

Figure 28: Equivalent von Mises plastic deformations in the backfill for Bridge 3-1 subject to different abutment displacements 


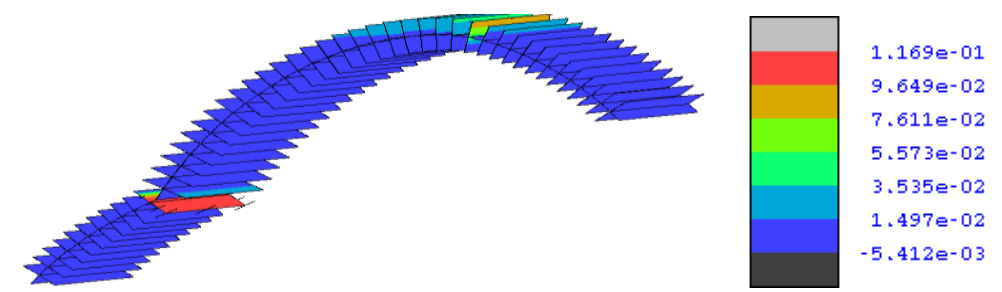

(a) Vertical differential settlement of support

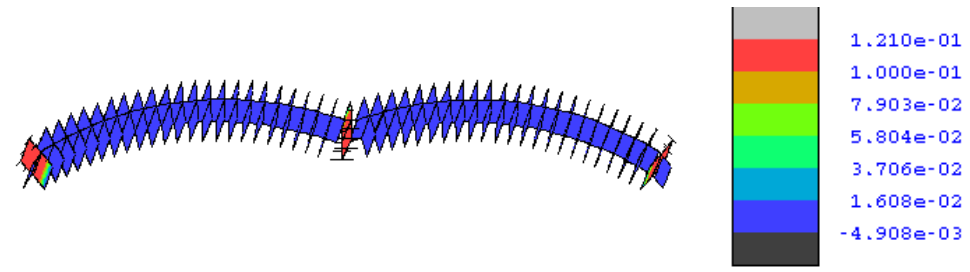

(b) Horizontal spread of support

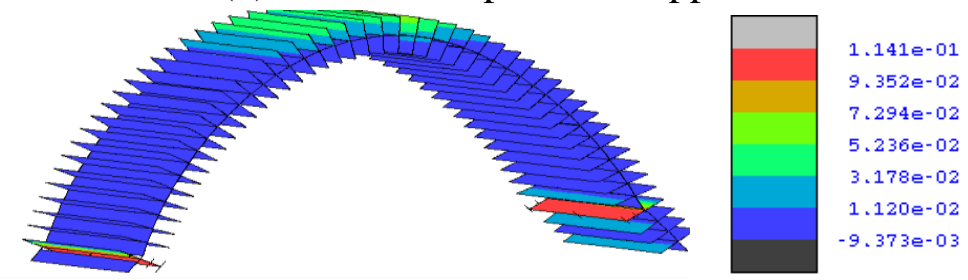

(c) Horizontal inward movement at the abutment

Figure 29: Plastic work $W_{p l 1}(\mathrm{~N} / \mathrm{mm})$ contour in the interface elements in the backfill for Bridge 3-1 subject to different abutment displacements

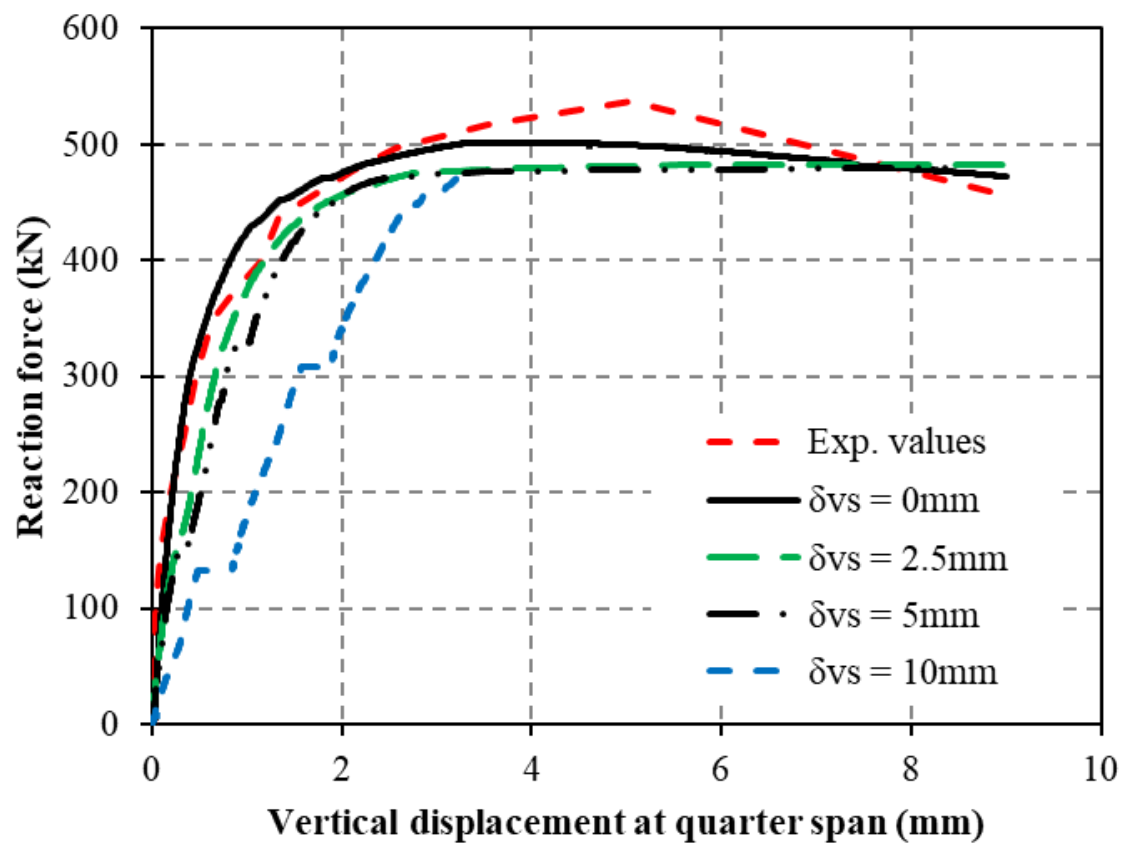

Figure 30: Effects of vertical settlement of left support 

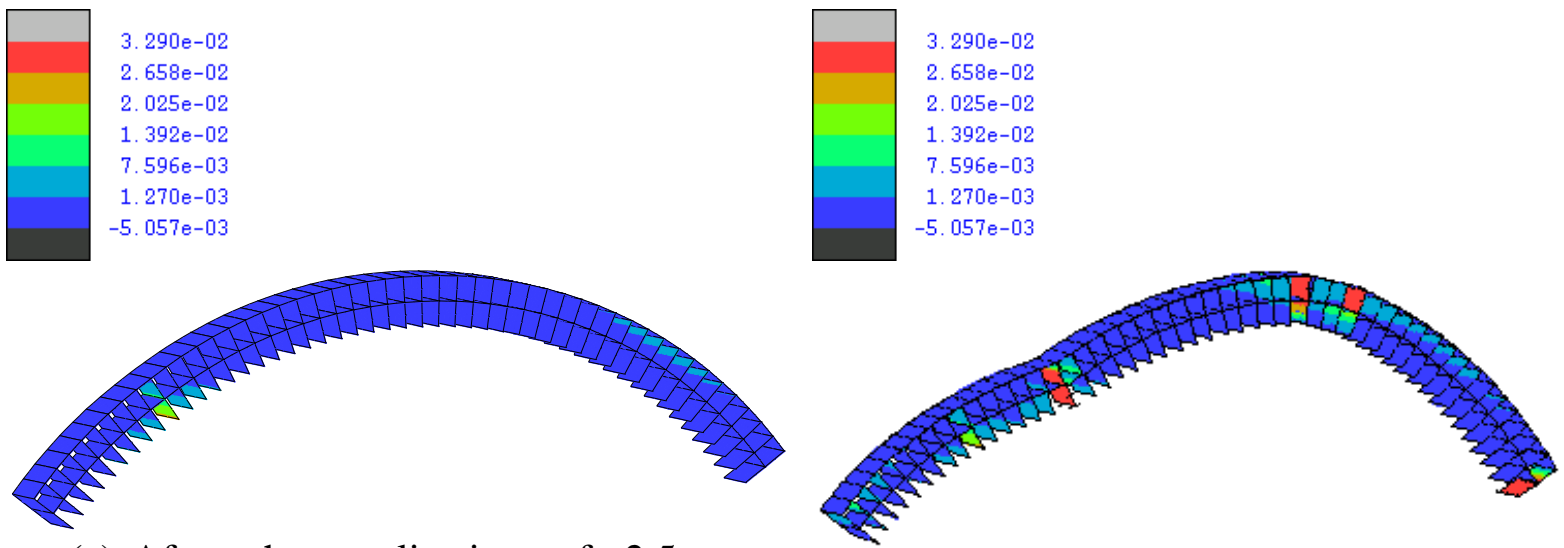

(a) After the application of $2.5 \mathrm{~mm}$ vertical settlement

(b) When vertical displacement $=4 \mathrm{~mm}$

Figure 31: Plastic work $W_{p l l}(\mathrm{~N} / \mathrm{mm})$ contours for Bridge 3-1 (a) after the application of 2.5 $\mathrm{mm}$ vertical settlement, (b) when vertical displacement $=4 \mathrm{~mm}$

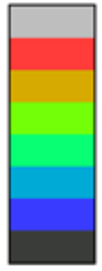

$$
\begin{array}{|l|}
\hline 5.000 e-03 \\
4.167 e-03 \\
3.333 e-03 \\
2.500 e-03 \\
1.667 e-03 \\
8.333 e-04 \\
0.000 e+00
\end{array}
$$

(a) After the application of $2.5 \mathrm{~mm}$ vertical settlement

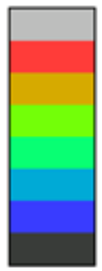

$$
\begin{array}{|l|}
\hline 5.000 e-03 \\
4.167 e-03 \\
3.333 e-03 \\
2.500 e-03 \\
1.667 e-03 \\
8.333 e-04 \\
0.000 e+00
\end{array}
$$

(b) When vertical displacement $=4 \mathrm{~mm}$

Figure 32: Equivalent von Mises plastic deformations in the backfill for Bridge 3-1 (a) after the application of $2.5 \mathrm{~mm}$ vertical settlement, (b) when vertical displacement $=4 \mathrm{~mm}$ 


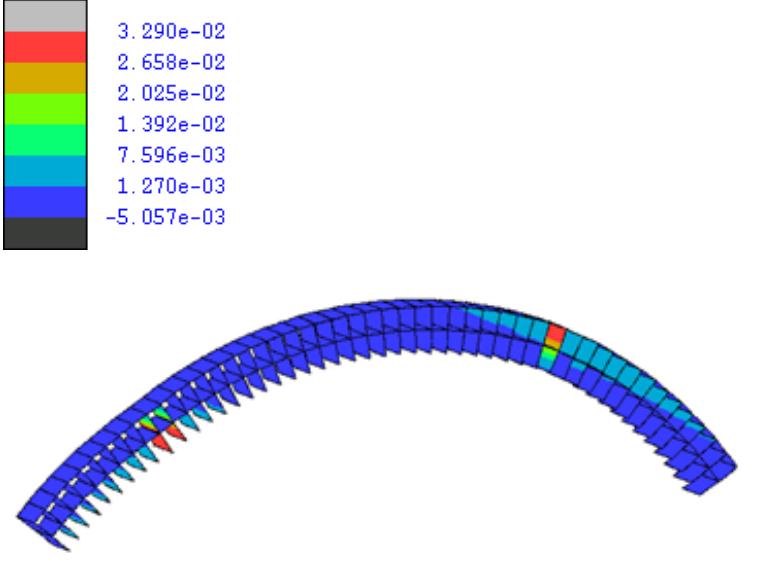

(a) After the application of $5 \mathrm{~mm}$ vertical settlement

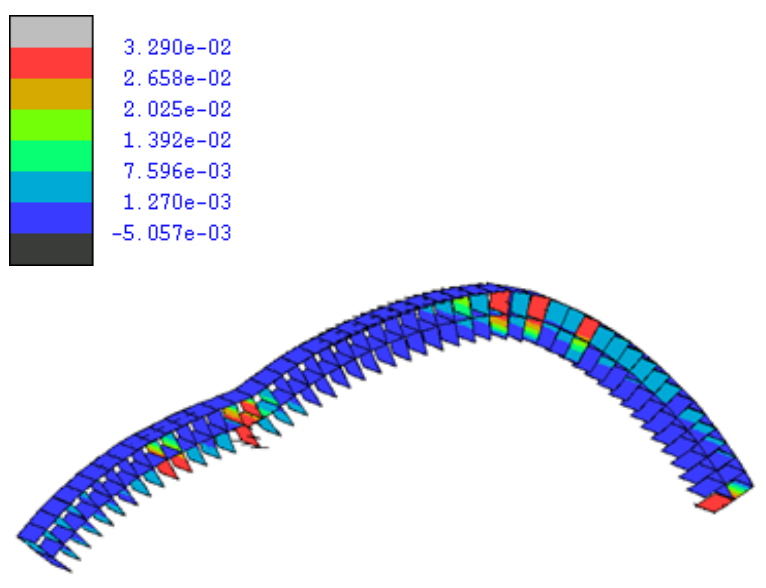

(b) When vertical displacement $=4 \mathrm{~mm}$

Figure 33: Plastic work $W_{p l l}(\mathrm{~N} / \mathrm{mm})$ contours for Bridge 3-1 (a) after the application of $10 \mathrm{~mm}$ vertical settlement, (b) when vertical displacement $=4 \mathrm{~mm}$

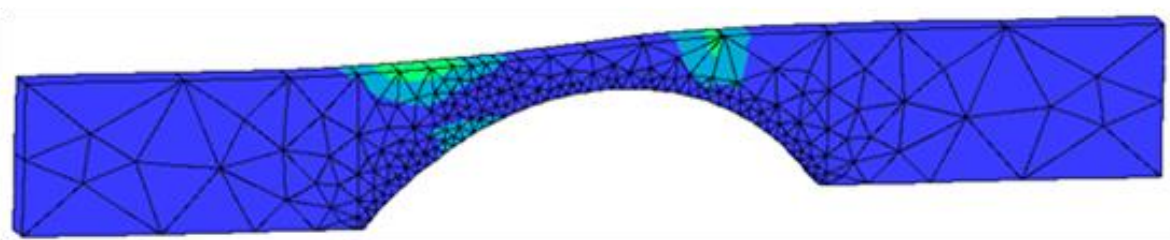

(a) After the application of $5 \mathrm{~mm}$ vertical settlement

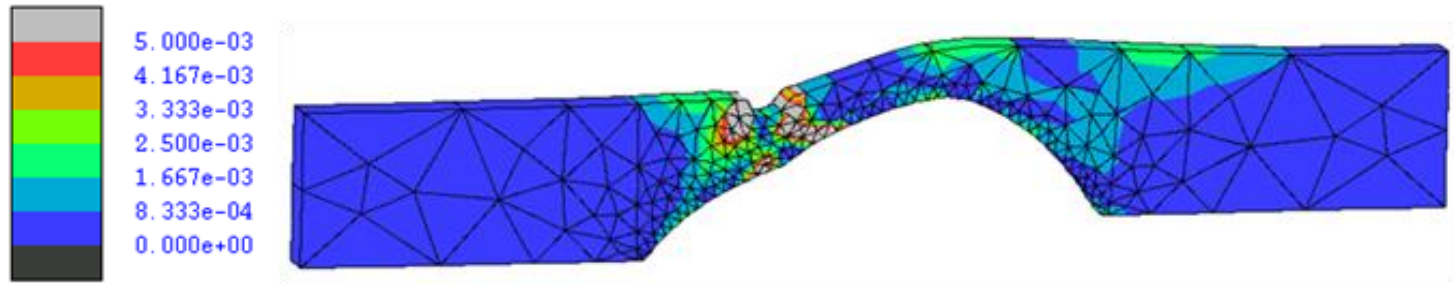

(b) When vertical displacement $=4 \mathrm{~mm}$

Figure 34: Equivalent von Mises plastic deformations in the backfill for Bridge 3-1 (a) after the application of $5 \mathrm{~mm}$ vertical settlement, (b) when vertical displacement $=4 \mathrm{~mm}$ 


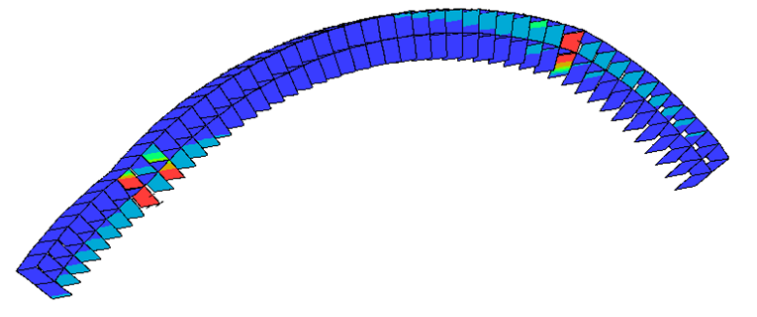

(c) After the application of $10 \mathrm{~mm}$ vertical settlement

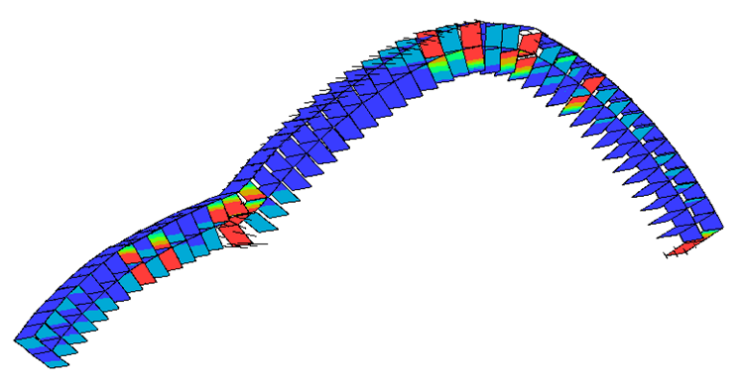

(d) When vertical displacement $=4 \mathrm{~mm}$

Figure 35: Plastic work $W_{p l 1}(\mathrm{~N} / \mathrm{mm})$ contours for Bridge 3-1 (a) after the application of $10 \mathrm{~mm}$ vertical settlement, (b) when vertical displacement $=4 \mathrm{~mm}$

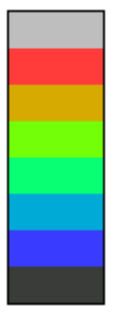

$$
\begin{aligned}
& 5.000 e-03 \\
& 4.167 e-03 \\
& 3.333 e-03 \\
& \text { 2. } 500 e-03 \\
& \text { 1. } 667 e-03 \\
& \text { 8. } 333 e-04 \\
& 0.000 e+00
\end{aligned}
$$

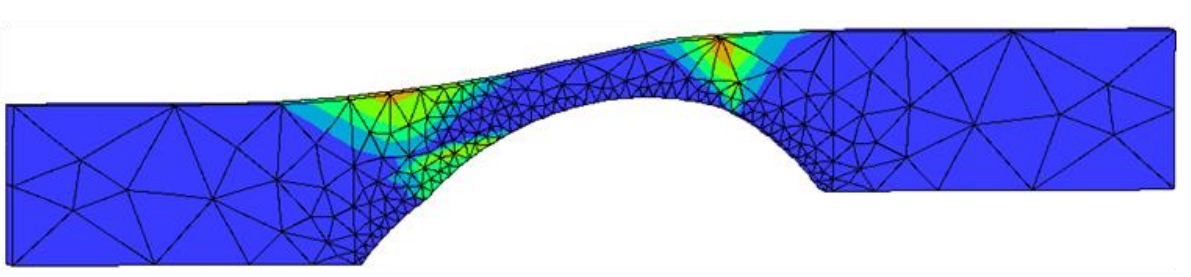

(a) After the application of $10 \mathrm{~mm}$ vertical settlement

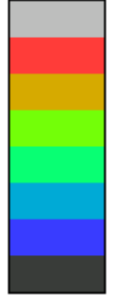
5. $000 \mathrm{e}-03$
4. $167 e-03$
3. $333 \mathrm{e}-03$
2. $500 \mathrm{e}-03$
1. $667 \mathrm{e}-03$
8. $333 \mathrm{e}-04$
0. $000 \mathrm{e}+00$

(b) When vertical displacement $=4 \mathrm{~mm}$

Figure 36: Equivalent von Mises plastic deformations in the backfill for Bridge 3-1 (a) after the application of $10 \mathrm{~mm}$ vertical settlement, (b) when vertical displacement $=4 \mathrm{~mm}$ 


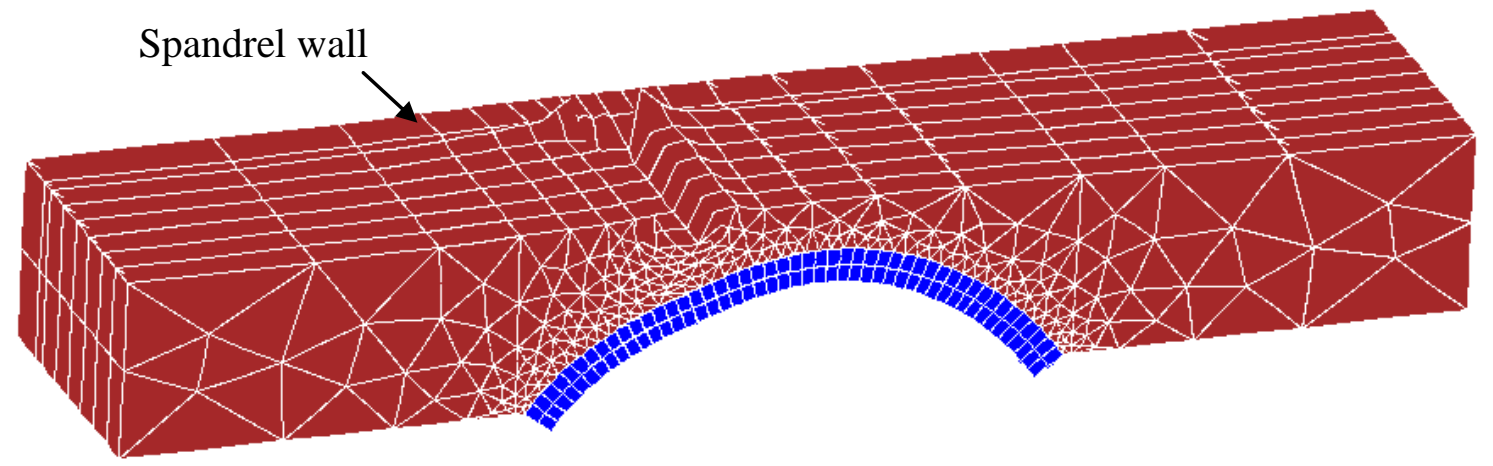

Figure 37: Deformed shape of Bridge 3-3 at last step of analysis

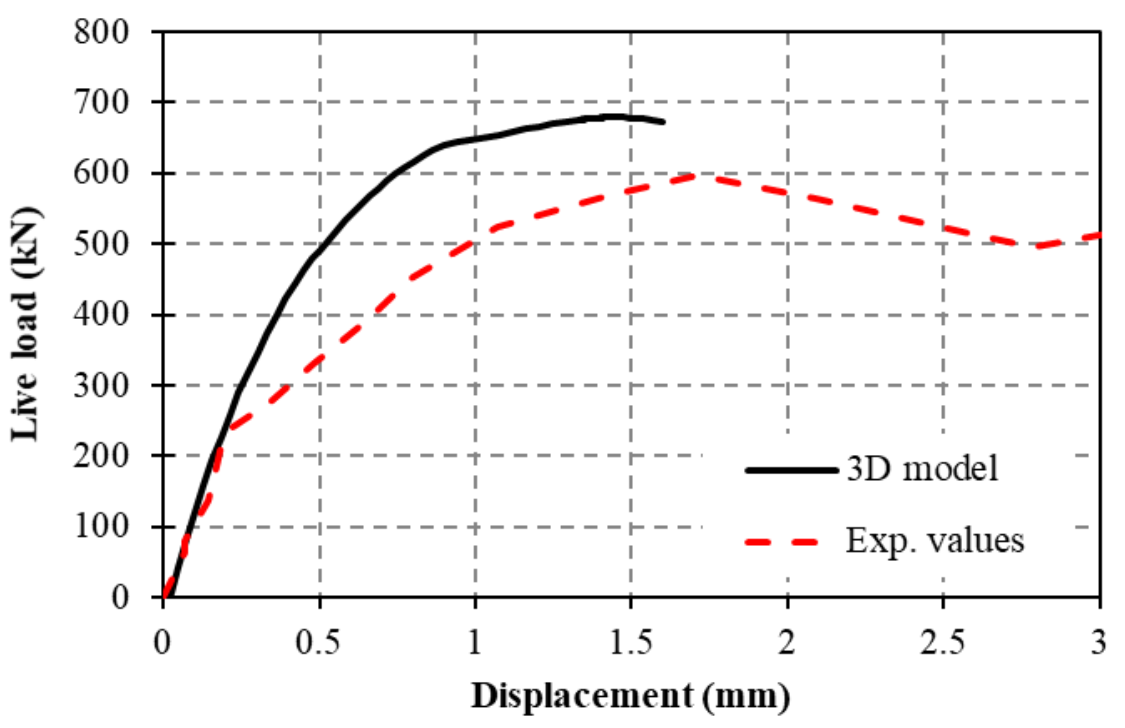

Figure 38: Load-displacement curves at quarter span of Bridge 3-3 

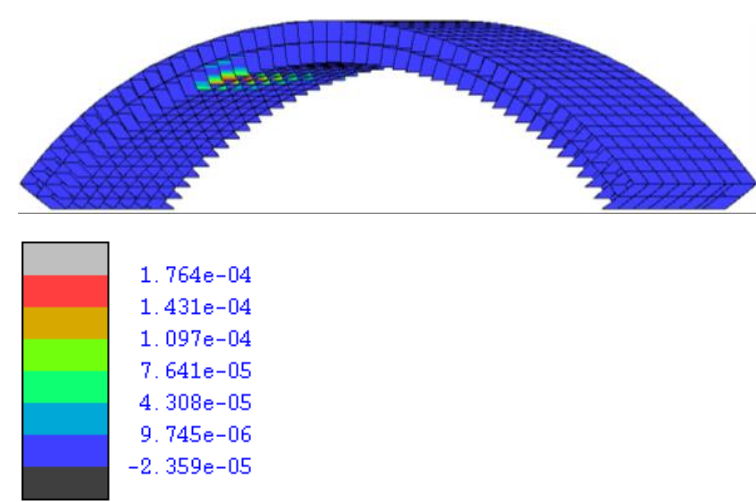

(a) $1^{\text {st }}$ radial crack $P=121 \mathrm{kN}$
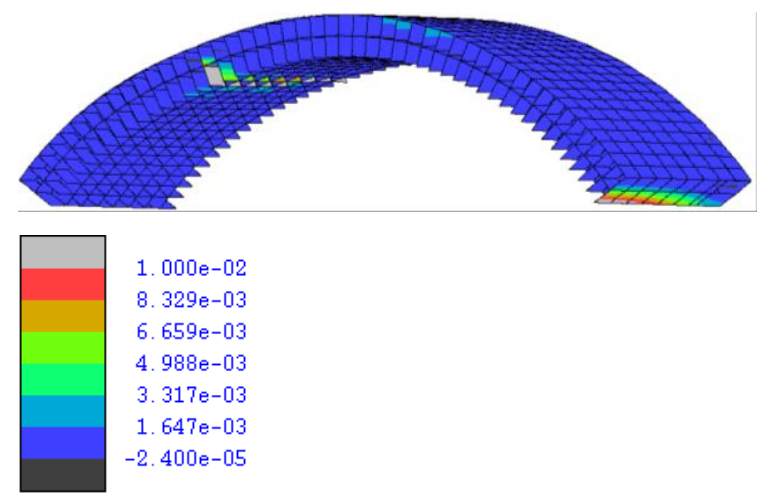

(c) $3^{\text {rd }}$ radial crack $P=557 \mathrm{kN}$

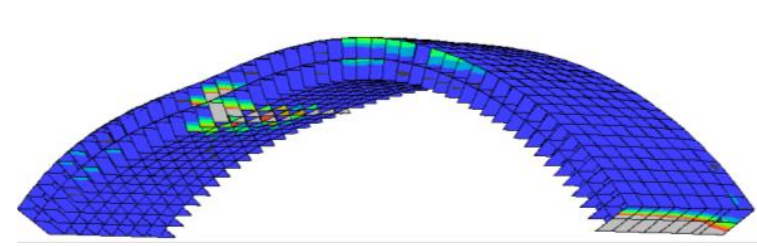

(e) Final step
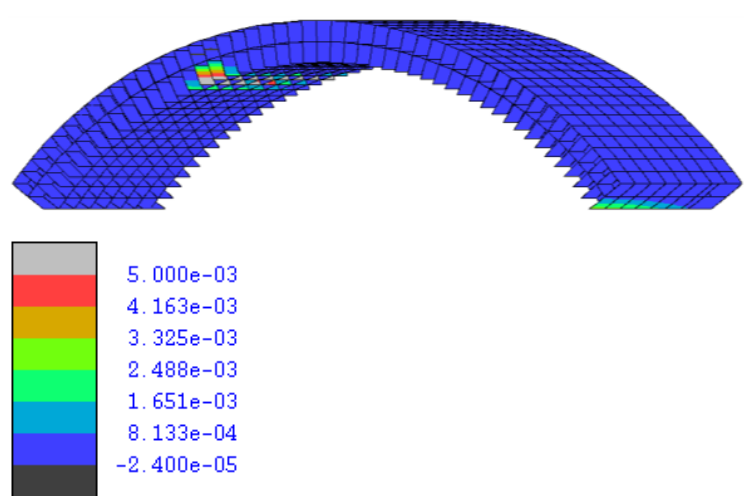

(b) $2^{\text {nd }}$ radial crack $P=374 \mathrm{kN}$
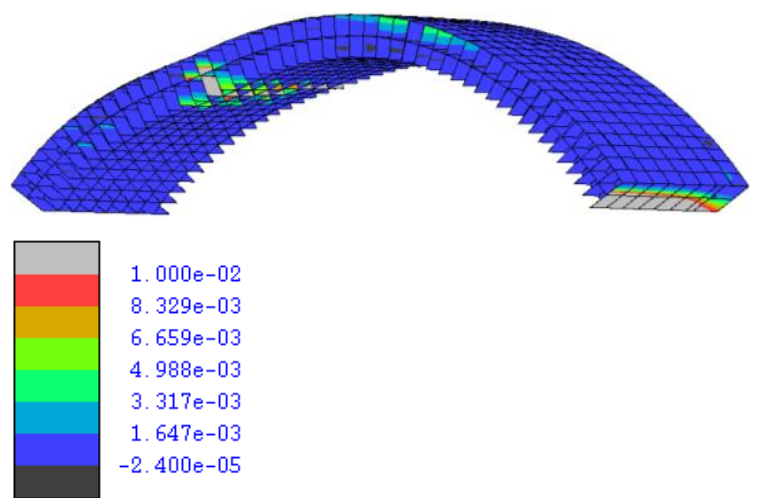

(d) $4^{\text {th }}$ radial crack $P=672 \mathrm{kN}$

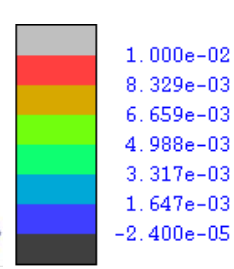

Figure 39: Plastic work $W_{p l l}(\mathrm{~N} / \mathrm{mm})$ contours at (a) $1^{\text {st }}$ radial crack $P=121 \mathrm{kN}$, (b) $2^{\text {nd }}$ radial crack $P=374 \mathrm{kN}$, (c) $3^{\text {rd }}$ radial crack $P=557 \mathrm{kN}$, (d) $4^{\text {th }}$ radial crack $P=672 \mathrm{kN}$ and (e) at the final step of analysis. 


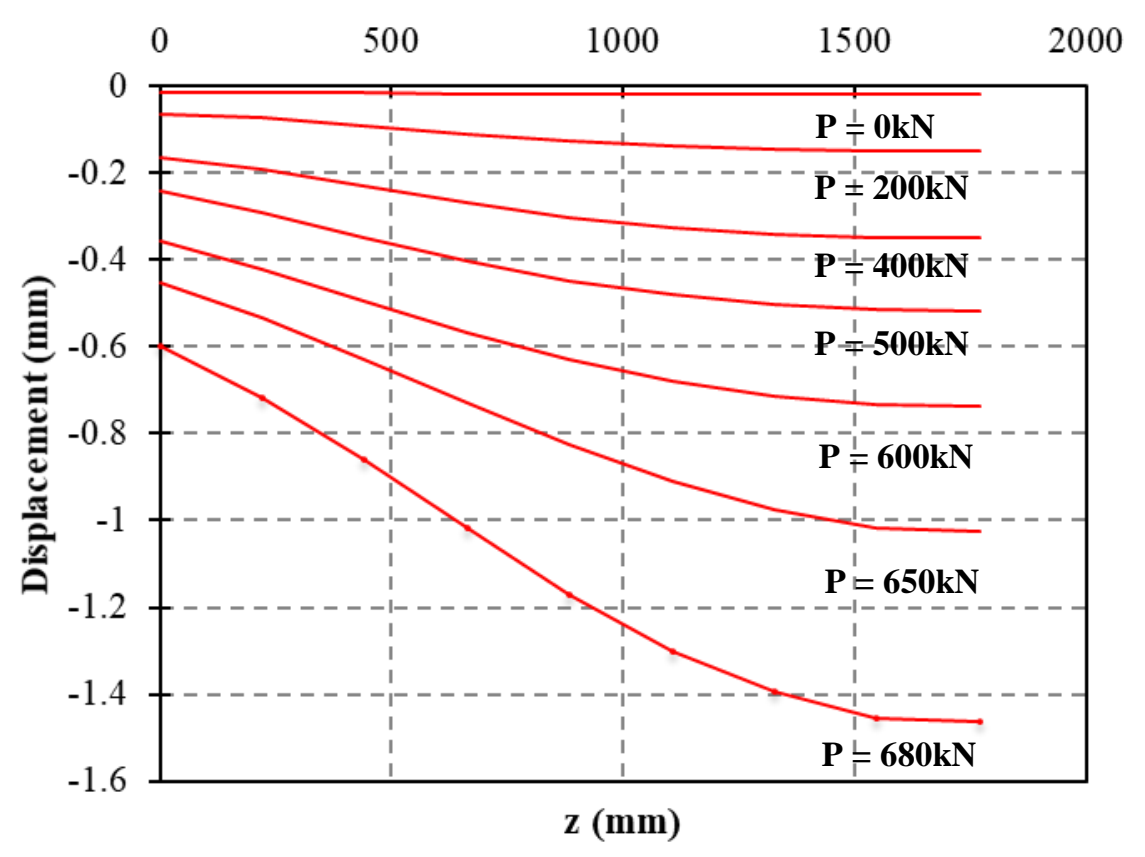

Figure 40: Displacements (in $\mathrm{mm}$ ) along the arch width (z direction) at different loading levels for the 3D model of Bridge 3-3 


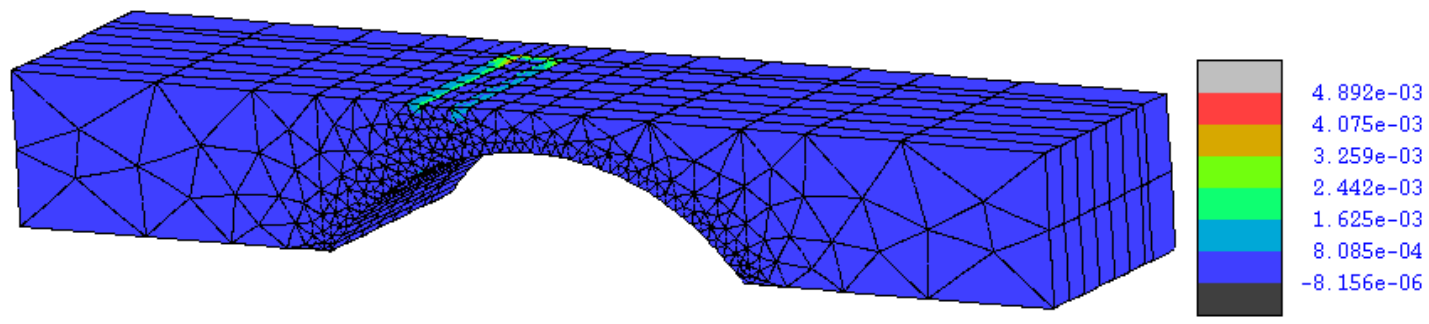

(a) $P=121 \mathrm{kN}$

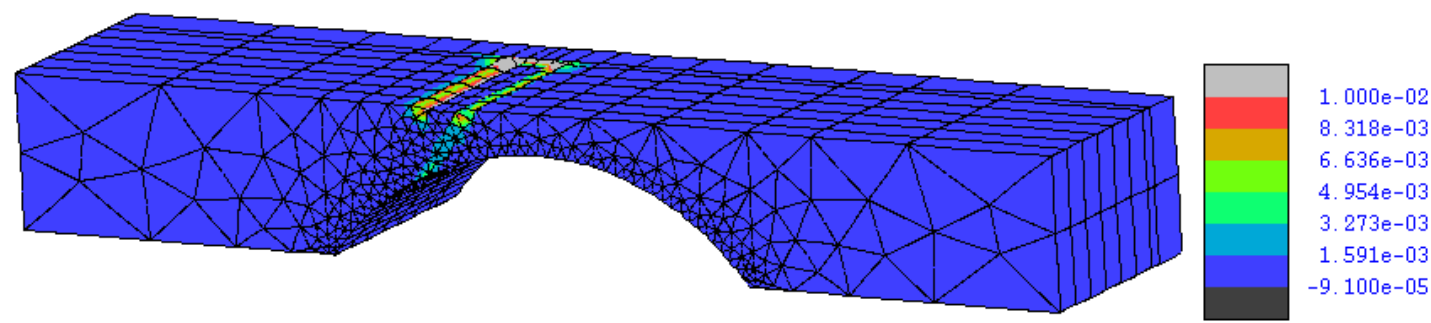

(b) $P=374 \mathrm{kN}$

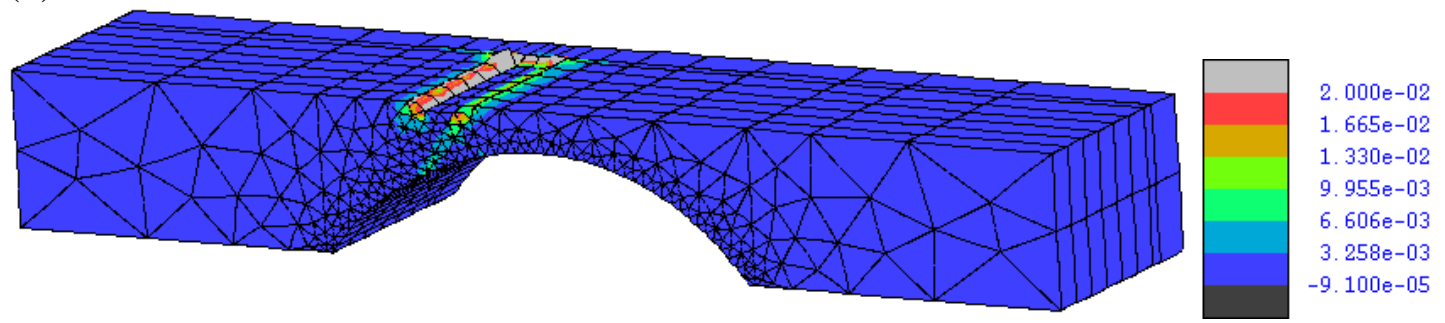

(c) $P=557 \mathrm{kN}$

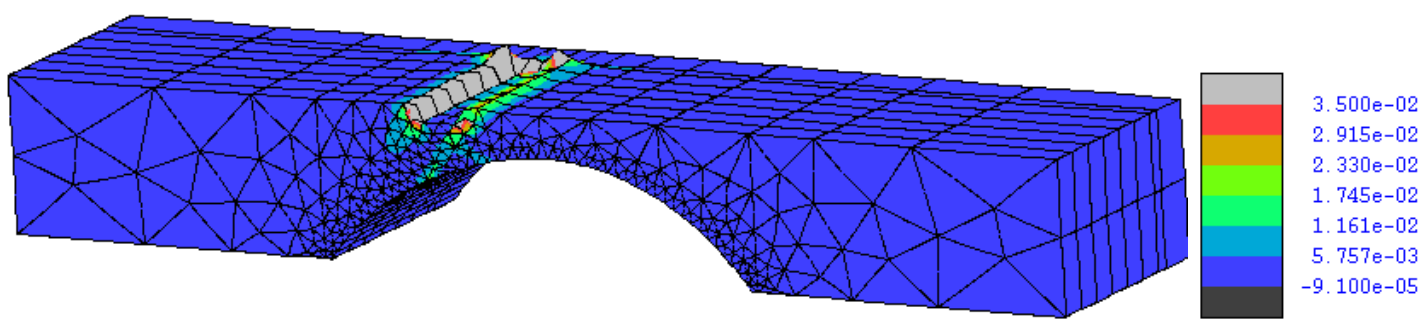

(d) $P=672 \mathrm{kN}$

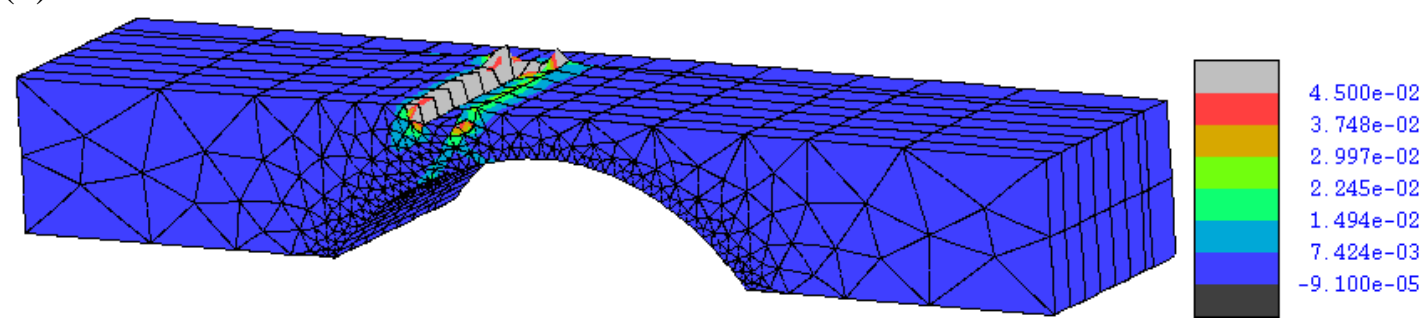

(e) Final step

Figure 41: Equivalent von Mises plastic deformations in the backfill at (a) $P=121 \mathrm{kN}$, (b) $P=374 \mathrm{kN}$, (c) $P=557 \mathrm{kN}$, (d) $P=672 \mathrm{kN}$ and (e) at the final step of analysis 


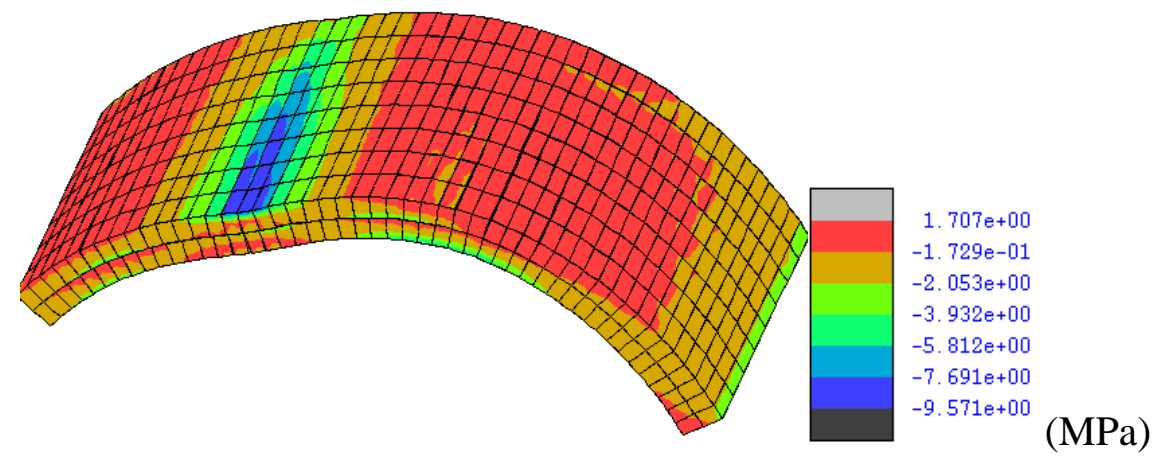

(a) Longitudinal stress $\sigma_{x x}$

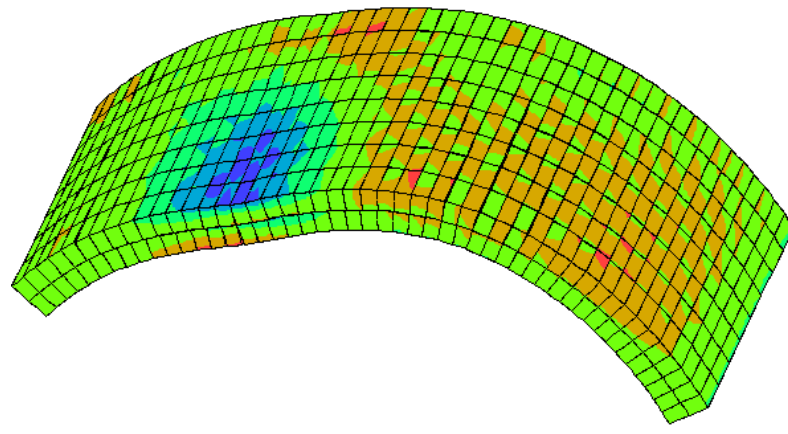

(b) Transverse stress $\sigma_{z z}$

Figure 42: Stress contour for the masonry arch barrel of the 3D model of Bridge 3-3

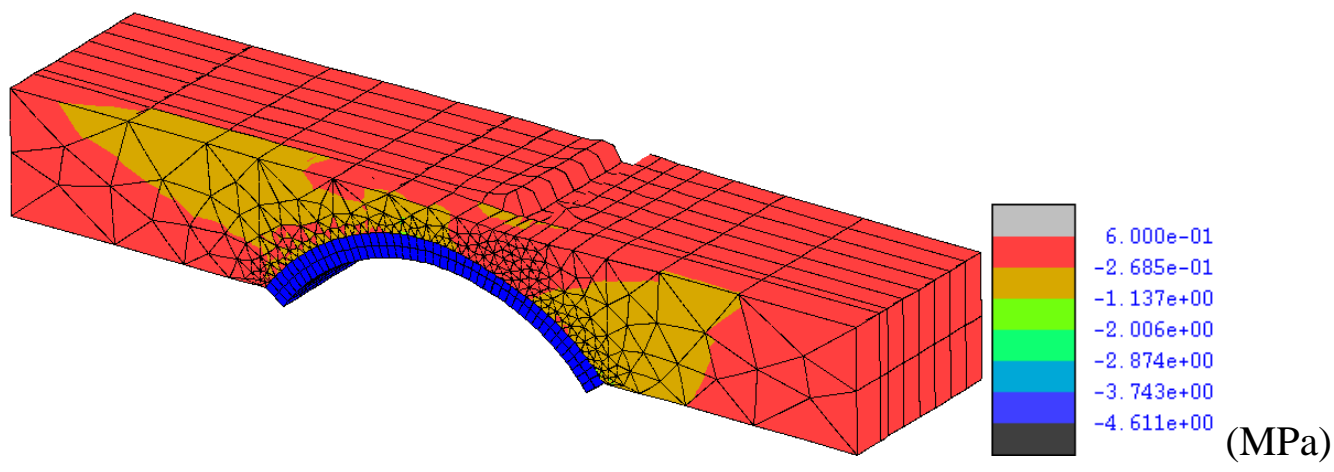

Figure 43: Spandrel wall longitudinal stresses $\left(\sigma_{x x}\right)$ contour

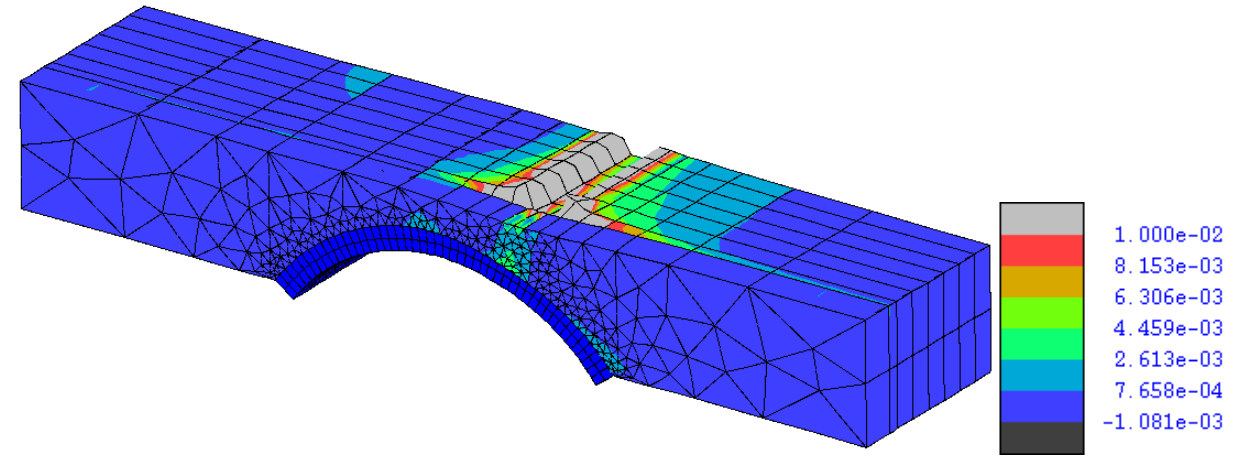

Figure 44: Spandrel wall equivalent Von Mises plastic deformations 